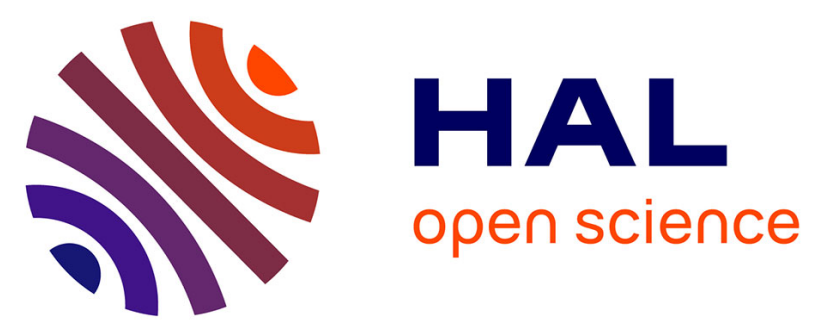

\title{
Electron-Rich 4-Substituted Spirobifluorenes: Toward a New Family of High Triplet Energy Host Materials for High-Efficiency Green and Sky Blue Phosphorescent OLEDs
}

Cassandre Quinton, Sébastien Thiery, Olivier Jeannin, Denis Tondelier, Bernard Geffroy, Emmanuel Jacques, Joëlle Rault-Berthelot, Cyril Poriel

\section{To cite this version:}

Cassandre Quinton, Sébastien Thiery, Olivier Jeannin, Denis Tondelier, Bernard Geffroy, et al.. Electron-Rich 4-Substituted Spirobifluorenes: Toward a New Family of High Triplet Energy Host Materials for High-Efficiency Green and Sky Blue Phosphorescent OLEDs. ACS Applied Materials \& Interfaces, 2017, 9 (7), pp.6194-6206. 10.1021/acsami.6b14285 . hal-01475815

HAL Id: hal-01475815 https://hal-univ-rennes1.archives-ouvertes.fr/hal-01475815

Submitted on 4 Jul 2017

HAL is a multi-disciplinary open access archive for the deposit and dissemination of scientific research documents, whether they are published or not. The documents may come from teaching and research institutions in France or abroad, or from public or private research centers.
L'archive ouverte pluridisciplinaire HAL, est destinée au dépôt et à la diffusion de documents scientifiques de niveau recherche, publiés ou non, émanant des établissements d'enseignement et de recherche français ou étrangers, des laboratoires publics ou privés. 


\title{
Electron-rich 4-substituted spirobifluorenes:
}

\author{
Towards a new family of high triplet energy host
}

\section{materials for high-efficiency green and sky blue}

\section{phosphorescent OLEDs}

Cassandre Quinton, ${ }^{a}$ Sébastien Thiery, ${ }^{a}$ Olivier Jeannin, ${ }^{a}$ Denis Tondelier, ${ }^{b}$ Bernard Geffroy, ${ }^{b, c}$

Emmanuel Jacques, ${ }^{d}$ Joëlle Rault-Berthelot, ${ }^{a^{*}}$ Cyril Poriel ${ }^{a^{*}}$

a: Institut des Sciences Chimiques de Rennes - UMR CNRS 6226 - Université Rennes 1- 35042 Rennes-France; b: LPICM, CNRS, Ecole Polytechnique, Université Paris Saclay, 91128, Palaiseau, France; c: LICSEN, NIMBE, CEA, CNRS, Université Paris-Saclay, CEA Saclay 91191 Gif-sur-Yvette Cedex, France, d. UMR CNRS 6164-Institut d'Électronique et des Télécommunications de Rennes- Département Microélectronique \& Microcapteurs, Bât.11B, Université Rennes 1, Campus de Beaulieu 35042 Rennes Cedex, France

\section{KEYWORDS}

Organic semiconductors, host materials, blue phosphorescent organic light-emitting diode, 4-substituted spirobifluorene, organic electronics, conjugation disruption 


\begin{abstract}
We report herein a detailed structure-properties relationship study of the first examples of electron-rich 4-substituted spirobifluorenes, namely 4-phenyl- $N$-carbazole-spirobifluorene (4-PhCz-SBF) and 4-(3,4,5-trimethoxyphenyl)-spirobifluorene $\quad\left(4-\mathbf{P h}(\mathbf{O M e})_{3}-\mathbf{S B F}\right) \quad$ for organic electronic
\end{abstract} applications. The incorporation of the electron-rich moieties in the ortho position of the biphenyl linkage (position $\mathrm{C} 4$ ) induces unique properties, very different to those previously described in the literature for this family of semiconductors. Both dyes can be readily synthesised, possess high triplet energies, excellent thermal stability and their HOMO energy levels are highly increased compared to other 4-substituted SBFs. We also provide in this work the first rationalization of the peculiar fluorescence of 4-substituted SBFs. Finally, the present dyes have been successfully incorporated as host in green and blue Phosphorescent Organic Light-Emitting Diodes with high performance either for the green (EQE of 20.2\%) or the blue colour (EQE of 9.6\%). These performances are, to the best of our knowledge, among the highest reported to date for 4-substituted SBF derivatives.

\title{
1. INTRODUCTION
}

For the last twenty years, organic semi-conductors constructed on the spirobifluorene (SBF) scaffold have encountered a fantastic development for Organic Electronic applications such as blue fluorescent emitter in Organic Light-Emitting Diodes (OLEDs), ${ }^{1-21}$ or in organic solar cells. $^{22-27}$ The very high performances obtained with some SBF based semi-conductors have hence turned spiroconfigured compounds as one of the most important family of compounds for electronics. 2-Substituted SBFs (see carbons labelling in Chart 1) are in this context the most developed class of SBF-based materials, the para linkage between the pendant substituent in position 2 and the constituted phenyl ring of the fluorene ensuring a good delocalization of $\pi$ - 
electrons. However, more recently, the growing necessity to design organic host materials for blue phosphors in Phosphorescent OLEDs (PhOLEDs) has led to new generations of SBF based materials with a wide energy gap (ca $4 \mathrm{eV}$ ) and a high triplet energy $\left(\mathrm{E}_{\mathrm{T}}\right)$. These key properties are the consequences of a restricted $\pi$-conjugation within these materials. Thus, SBF compounds substituted in the ortho position of the biphenyl linkage (position $\mathrm{C} 4$, see carbons labelling in Chart 1) have encountered a great interest. Indeed, in 4-substituted SBFs, there is, due to the ortho linkage, a strong steric congestion which leads to an efficient $\pi$-conjugation disruption between the fluorene and its C4 pendant substituent. Despite these very appealing properties, only few examples of 4-substituted SBFs as host materials for blue and green PhOLEDs have been reported to date. These molecules incorporate either pure hydrocarbon fragments such as a phenyl $^{28}$ or a spirobifluorene core ${ }^{29-31}$ or electron accepting moieties such as pyridine, ${ }^{32}$ pyrimidine $^{33}$ or diphenylphosphine oxide. ${ }^{34,35}$ Thus, and despite the $\pi$-conjugation disruption between the fluorene and its substituent in $\mathrm{C} 4$, it has been shown in these previous works that electron-withdrawing groups such as pyridine isomers or pyrimidine (Chart 1) can selectively decrease the LUMO energy levels (localized on the electron poor moiety and/or on the adjacent fluorene core) keeping nevertheless the HOMO energy level (localized on the SBF core) unaltered. $^{32,33}$ However, the opposite strategy, that is increasing the HOMO energy level of 4-substituted SBFs, has to the best of our knowledge never been explored.
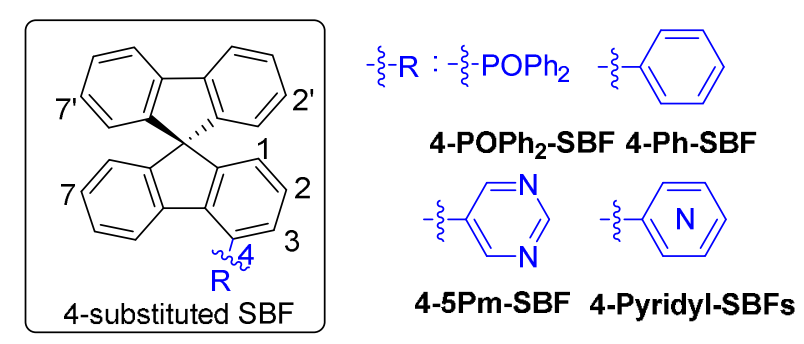

Chart 1. Examples of 4-substituted SBFs previously reported in the literature. ${ }^{32-35}$ 
As it is known that the increase of HOMO energy levels through the incorporation of phenylacridine $^{36-39}$ indoloacridine ${ }^{40-42}$ quinolinophenothiazine $^{43}$ or quinolinophenoxazine $^{44}$ moieties instead of a fluorene core has remarkable consequences on the device performance we wish to report herein the first examples of 4-substituted SBF derivatives incorporating electronrich fragments, namely $N$-phenylcarbazole in 4-PhCz-SBF and trimethoxyphenyl in 4-Ph(OMe) $)_{3}$-SBF, Scheme 1. Through a detailed structure-properties relationship study with the corresponding building blocks, namely 4-phenyl-spirobifluorene (4-Ph-SBF), spirobifluorene (SBF), 1,2,3-trimethoxybenzene $\left(\mathbf{P h}(\mathbf{O M e})_{3}\right)$ and N-phenyl-carbazole (N-PhCz), we highlight herein the remarkable influence of the C4-substituent on the electronic properties. Both dyes can be readily synthesised, possess high $\mathrm{E}_{\mathrm{T}}$, excellent thermal stability and their HOMO energy levels are highly increased compared to other 4-substituted SBFs reported to date. In addition, both dyes display very different fluorescence properties and we provide herein the first rationalization of the peculiar fluorescence of 4-substituted SBFs. Finally, both 4-PhCz-SBF and 4-Ph(OMe) $)_{3}$-SBF have been successfully incorporated as host in green and blue PhOLEDs

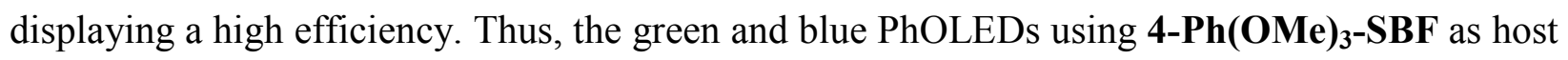
display a high EQE of $20.2 \%$ and $9.6 \%$ respectively. These performances are, to the best of our knowledge, among the highest reported to date for 4-substituted SBF derivatives and highlight the efficiency of the present design strategy.

\section{EXPERIMENTAL SECTION}

2.1. General method. Materials and methods for syntheses, X-Ray, thermal and electrochemical studies, photophysics, theoretical calculations and devices fabrication and characterization are provided in SI. 
2.2 Synthesis. Synthesis of 4-PhCz-SBF. 4-Bromo-9,9'-spirobi[fluorene] 4-Br-SBF ${ }^{32}$ (0.76 g, 1.9 mmol, 1.0 eq), 9-(4-(4,4,5,5-tetramethyl-1,3,2-dioxaborolan-2-yl)phenyl)-9H-carbazole (0.71 $\mathrm{g}, 1.9 \mathrm{mmol}, 1.0 \mathrm{eq})$, potassium carbonate $(2.7 \mathrm{~g}, 20 \mathrm{mmol}, 10 \mathrm{eq})$ and $\mathrm{Pd}(\mathrm{dppf}) \mathrm{Cl}_{2}(0.083 \mathrm{~g}$, $0.10 \mathrm{mmol}, 0.05 \mathrm{eq})$ were dissolved in dry DMF $(25 \mathrm{~mL})$ under an argon atmosphere. The mixture was heated up to reflux and stirred overnight. After cooling to room temperature, saturated solution of ammonium chloride $(50 \mathrm{~mL})$ was added, and organic layer was extracted with dichloromethane $(3 \times 50 \mathrm{~mL})$. The combined organic extracts were dried over magnesium sulfate, filtered, and concentrated under reduced pressure. The residue was purified by flash chromatography on silica gel to afford the title compound as a colourless solid (0.80 g, 1.4 mmol). [column conditions: Silica cartridge $(24 \mathrm{~g})$; solid deposit on Celite $\AA$; $\lambda$ detection: (254 $\mathrm{nm}, 280 \mathrm{~nm}$ ); dichloromethane in light petroleum 1:9 at $20 \mathrm{~mL} / \mathrm{min}$; collected fraction: 20-35 min. Recristallized from ethanol. Yield: 75\%; m.p: $198^{\circ} \mathrm{C}$; IR (ATR, $\left.\mathrm{cm}^{-1}\right): v=567,621,642$, $677,723,746,806,839,916,1003,1018,1171,1228,1315,1334,1361,1448,1477,1514$, 1599, 2952, 3020, 3041, 3058; ${ }^{1} \mathrm{H}$ NMR (300 MHz, $\left.\mathrm{CD}_{2} \mathrm{Cl}_{2}\right) \delta: 8.22(\mathrm{ddd}, \mathrm{J}=7.8,1.2,0.8 \mathrm{~Hz}$, 2H, ArH, $\left.\mathrm{H}_{14}\right), 7.94-7.87\left(\mathrm{~m}, 4 \mathrm{H}, \mathrm{ArH}, \mathrm{H}_{4}, \mathrm{H}_{5}, \mathrm{H}_{9}\right), 7.80\left(\mathrm{~d}, \mathrm{~J}=8.6 \mathrm{~Hz} 2 \mathrm{H}, \mathrm{ArH}, \mathrm{H}_{10}\right), 7.63$ $\left(\mathrm{dt}, \mathrm{J}=8.3,0.9 \mathrm{~Hz}, 2 \mathrm{H}, \mathrm{ArH}, \mathrm{H}_{11}\right), 7.51\left(\mathrm{ddd}, \mathrm{J}=8.3,7.1,1.2 \mathrm{~Hz}, 2 \mathrm{H}, \mathrm{ArH}, \mathrm{H}_{12}\right), 7.43(\mathrm{td}, \mathrm{J}=$ 7.5, 1.1 Hz, 2H, ArH, $\mathrm{H}_{3}, \mathrm{H}_{6}$ ) $) 7.38$ - 7.32 (m, 3H, ArH, $\left.\mathrm{H}_{3}, \mathrm{H}_{13}\right), 7.28$ (ddd, J = 7.8, 1.2, 0.7 Hz, 1H, ArH, $\mathrm{H}_{5}$ ), 7.24 - 7.14 (m, 4H, ArH, $\left.\mathrm{H}_{2}, \mathrm{H}_{2}, \mathrm{H}_{7}, \mathrm{H}_{6}\right), 7.07$ (td, J = 7.4, $\left.1.3 \mathrm{~Hz}, 1 \mathrm{H}, \mathrm{ArH}, \mathrm{H}_{7}\right)$, $6.82\left(\mathrm{dt}, \mathrm{J}=7.6,1.0,2 \mathrm{H}, \mathrm{ArH}, \mathrm{H}_{1}, \mathrm{H}_{8^{\prime}}\right), 6.73\left(\mathrm{dd}, \mathrm{J}=7.6,1.1 \mathrm{~Hz}, 1 \mathrm{H}, \mathrm{ArH}, \mathrm{H}_{1}\right), 6.69(\mathrm{ddd}, \mathrm{J}=$ 7.5, 1.2, $\left.0.7 \mathrm{~Hz}, 1 \mathrm{H}, \mathrm{ArH}, \mathrm{H}_{8}\right)$, see labelling in SI; ${ }^{13} \mathrm{C} \mathrm{NMR}\left(75 \mathrm{MHz}, \mathrm{CD}_{2} \mathrm{Cl}_{2}\right) \delta: 150.2(\mathrm{C})$, 149.8 (C), 149.5 (C), 142.5 (C), 142.1 (C), 141.5 (C), 140.7 (C), 139.4 (C), 137.7 (C, 2 peaks), $131.4(\mathrm{CH}), 130.4(\mathrm{CH}), 128.47(\mathrm{CH}), 128.45(\mathrm{CH}), 128.3(\mathrm{CH}), 128.04(\mathrm{CH}), 127.97(\mathrm{CH})$, $127.7(\mathrm{CH}), 126.6(\mathrm{CH}), 124.40(\mathrm{CH}), 124.37(\mathrm{CH}), 124.1(\mathrm{C}), 123.7(\mathrm{CH}), 123.6(\mathrm{CH}), 120.9$ 
(CH), $120.8(\mathrm{CH}), 120.7(\mathrm{CH}), 110.5(\mathrm{CH}), 66.4\left(\mathrm{C}\right.$ Spiro); HRMS (ASAP+, 500 $\left.{ }^{\circ} \mathrm{C}\right)$ calculated for $\mathrm{C}_{43} \mathrm{H}_{28} \mathrm{~N}$ : 558.2222, found: $558.2224[\mathrm{M}+\mathrm{H}]^{+}$; Elemental analysis for $\mathrm{C}_{43} \mathrm{H}_{27} \mathrm{~N}$ : C, 92.61\%; H: 4.88\%; N: 2.51\%. Found: C; 92.58\%; H, 4.99\%; N: 2.50\%; $\lambda$ abs $[\mathrm{nm}]\left(\varepsilon\left[10^{4} . \mathrm{L} \cdot \mathrm{mol}^{-1} . \mathrm{cm}^{-1}\right]\right)=$ $293(3.7), 309(2.8), 340(0.7)$

Synthesis of 4-Ph(OMe) $)_{3}$-SBF. 4-Br-SBF (0.75 g, 1.9 mmol, 1.0 eq), (3,4,5-trimethoxyphenyl)boronic acid (0.54 g, $2.6 \mathrm{mmol}, 1.4 \mathrm{eq})$, potassium carbonate (1.3 g, $9.5 \mathrm{mmol}, 5.0 \mathrm{eq})$ and $\mathrm{Pd}(\mathrm{dppf}) \mathrm{Cl}_{2}(0.066 \mathrm{~g}, 0.081 \mathrm{mmol}, 0.04 \mathrm{eq})$ were dissolved in dry DMF $(20 \mathrm{~mL})$ under an argon atmosphere. The mixture was heated up to reflux and stirred overnight. After cooling to room temperature, saturated solution of ammonium chloride $(50 \mathrm{~mL})$ was added, and organic layer was extracted with dichloromethane $(3 \times 50 \mathrm{~mL})$. The combined organic extracts were dried over magnesium sulfate, filtered, and concentrated under reduced pressure. The residue was purified by flash chromatography on silica gel to afford the title compound as a colourless solid (0.76 g, $1.6 \mathrm{mmol})$. [column conditions: Silica cartridge ( $24 \mathrm{~g})$; solid deposit on Celite $\AA$; $\lambda$ detection: $(254$ $\mathrm{nm}, 280 \mathrm{~nm}$ ); dichloromethane in light petroleum 1:9 at $20 \mathrm{~mL} / \mathrm{min}$; collected fraction: 20-35 min. Yield: 83\%; m.p: $215^{\circ} \mathrm{C}$; IR $\left(A T R, \mathrm{~cm}^{-1}\right): v=658,669,731,748,840,899,972,997,1043$, 1122, 1167, 1255, 1303, 1359, 1377, 1452, 2838, 2871, 2885, 2908, 2943; ${ }^{1} \mathrm{H}$ NMR (300 MHz, $\left.\mathrm{CD}_{2} \mathrm{Cl}_{2}\right) \delta: 7.90\left(\mathrm{ddd}, \mathrm{J}=7.7,1.1,0.7 \mathrm{~Hz}, 2 \mathrm{H}, \mathrm{ArH}, \mathrm{H}_{4}, \mathrm{H}_{5}\right.$ ) $), 7.40(\mathrm{td}, \mathrm{J}=7.5,1.1 \mathrm{~Hz}, 2 \mathrm{H}, \mathrm{ArH}$, $\mathrm{H}_{3}, \mathrm{H}_{6}$ ), 7.21 (m, 2H, ArH, $\left.\mathrm{H}_{6}, \mathrm{H}_{3}\right), 7.18$ - 7.12 (m, 3H, ArH, $\left.\mathrm{H}_{2}, \mathrm{H}_{7}, \mathrm{H}_{7}\right), 7.12$ - 7.07 (m, 1H, ArH, $\left.\mathrm{H}_{5}\right), 7.03\left(\mathrm{td}, \mathrm{J}=7.4,1.4 \mathrm{~Hz}, 1 \mathrm{H}, \mathrm{ArH}, \mathrm{H}_{2}\right), 6.83\left(\mathrm{~s}, 2 \mathrm{H}, \mathrm{ArH}, \mathrm{H}_{9}\right), 6.81-6.75(\mathrm{~m}, 2 \mathrm{H}$, ArH, $\mathrm{H}_{1}, \mathrm{H}_{8}$ ), 6.69 - 6.62 (m, 2H, ArH, $\left.\mathrm{H}_{1}, \mathrm{H}_{8}\right), 3.92$ (s, 3H, $\left.\mathrm{CH}_{3}, \mathrm{H}_{11}\right), 3.90$ (s, 6H, CH $\mathrm{CH}_{30}$ ), see labelling in SI; ${ }^{13} \mathrm{C}$ NMR (75 MHz, $\left.\mathrm{CD}_{2} \mathrm{Cl}_{2}\right) \delta$ : $154.1(\mathrm{C}), 150.0$ (C), 149.7 (C), 149.6 (C), 142.5 (C), 142.2 (C), 139.2 (C), 138.6 (C), 138.4 (C), 137.0 (C), $130.2(\mathrm{CH}), 128.4(\mathrm{CH}, 2$ peaks), $128.1(\mathrm{CH}), 127.9(\mathrm{CH}), 127.8(\mathrm{CH}), 124.4(\mathrm{CH}), 124.2(\mathrm{CH}), 123.9(\mathrm{CH}), 123.4(\mathrm{CH})$, 
$120.8(\mathrm{CH}), 107.0(\mathrm{CH}), 66.3\left(\mathrm{C}\right.$ spiro), $61.3\left(\mathrm{CH}_{3}\right), 56.8\left(\mathrm{CH}_{3}\right) ; \mathrm{HRMS}\left(\mathrm{ESI}+, \mathrm{CH}_{3} \mathrm{OH} / \mathrm{CH}_{2} \mathrm{Cl}_{2}\right.$ : 95/5) calculated for $\mathrm{C}_{34} \mathrm{H}_{26} \mathrm{O}_{3} \mathrm{Na}$ : 505.1780, found: 505.1781 [M+Na] ${ }^{+}$; Elemental analysis for $\mathrm{C}_{34} \mathrm{H}_{26} \mathrm{O}_{3}: \mathrm{C}, 84.62 \%$; H, 5.43\%. Found: C, 84.24\%; H, 5.51\%; $\lambda$ abs [nm] $\left(\varepsilon\left[10^{4} . \mathrm{L} . \mathrm{mol}^{-1} . \mathrm{cm}^{-1}\right]\right)=$ 297 (1.0), 309 (1.7).

\section{RESULTS AND DISCUSSIONS}

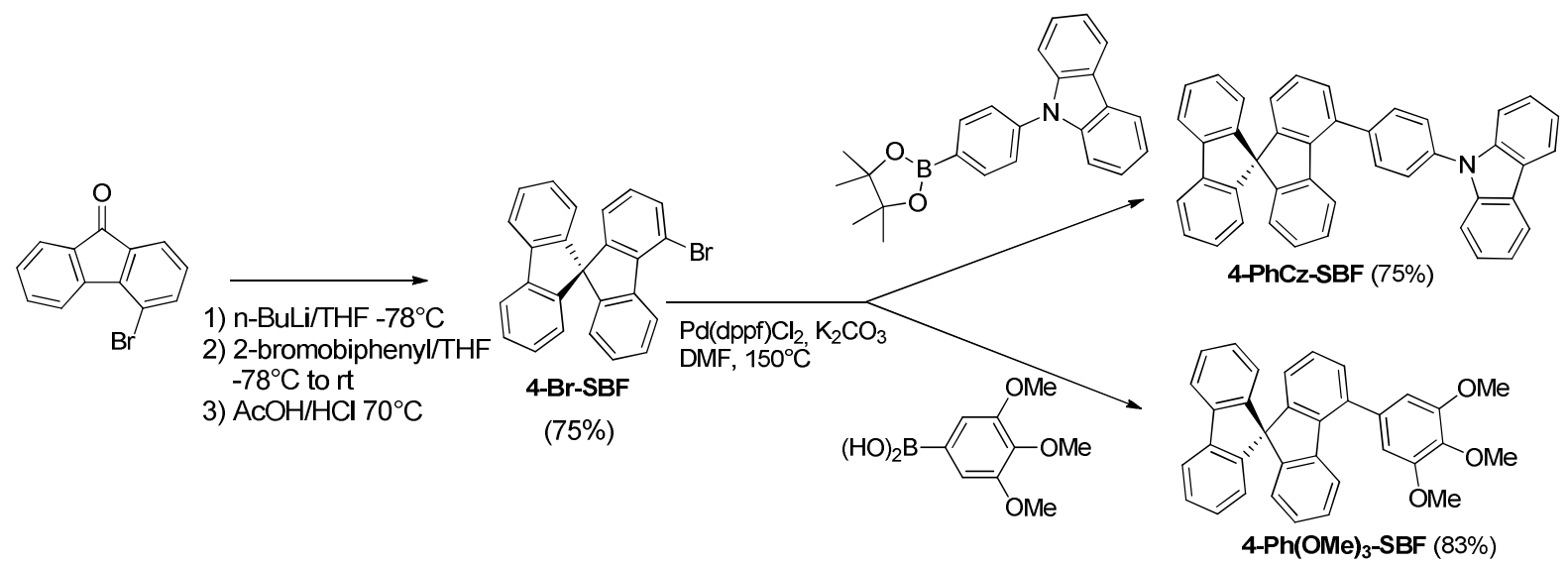

Scheme 1. Synthesis of 4-Ph(OMe) $)_{3}-\mathrm{SBF}$ and of 4-PhCz-SBF.

As shown in scheme 1 , both molecules were readily synthesised by a Miyaura-Suzuki coupling between the key platform 4-bromo-9,9'-spirobi[fluorene] 4-Br-SBF (synthesized from the 4-bromofluorenone derivative $)^{32}$ and either 9-(4-(4,4,5,5-tetramethyl-1,3,2-dioxaborolan-2yl)phenyl)-9H-carbazole or 3,4,5-trimethoxyphenylboronic acid providing with high yield 9-(4(9,9'-spirobi[fluoren]-4-yl)phenyl)-9H-carbazole (4-PhCz-SBF, yield: 75\%) or 4-(3,4,5-trimethoxyphenyl)-9,9'-spirobi[fluorene] (4-Ph(OMe)3-SBF, yield: 83\%). This short and efficient synthetic approach allows a gram-scale preparation and purification, key feature for further device fabrication.

At this stage, the fine analyses of the ${ }^{1} \mathrm{H}$ NMR spectra of 4-Ph(OMe) ${ }_{3}-\mathbf{S B F}$ and $\mathbf{4 - P h C z - S B F}$ can provide interesting information on the influence of the pendant substituent on the chemical shift of the hydrogen atoms of the fluorene. The complete assignments of all signals have been 
performed by 2D NMR spectroscopy experiments (HMBC, HSQC, ${ }^{1} \mathrm{H} /{ }^{1} \mathrm{H}$ COSY, see SI). Thus, in the ${ }^{1} \mathrm{H}$ NMR spectrum of $\mathbf{4 - P h}(\mathbf{O M e})_{3}-\mathbf{S B F}$, the hydrogen atom $\mathrm{H} 3$ of the fluorene (see chart 1) in $\alpha$ position of the 3,4,5-trimethoxyphenyl linkage is detected at $7.21 \mathrm{ppm}$, that is identical to that of the model compound 4-Ph-SBF $\left(\delta_{\mathrm{H} 3}=7.21 \mathrm{ppm}\right)$, see ${ }^{1} \mathrm{H}$ NMR spectra in SI. Switching from a 3,4,5-trimethoxyphenyl moiety to a $N$-phenylcarbazole moiety in 4-PhCz-SBF leads to a non-negligible deshielding of $0.15 \mathrm{ppm}\left(\delta_{\mathrm{H} 3}=7.36 \mathrm{ppm}\right)$, highlighting the different influence of the $\mathrm{C} 4$ substituent on the hydrogens chemical shifts of the fluorene backbone. This feature can be correlated to the angle formed between the fluorene and its substituent (see below the X-Ray structures). Indeed, the wider the angle, the weaker the electronic effects on the chemical shifts of the hydrogen atoms. One can note that this effect decreases as the distance to the linkage increases $\left(\delta_{\mathrm{H} 1}=6.65 \mathrm{ppm} \text { for 4-Ph(OMe }\right)_{3}$-SBF, $6.67 \mathrm{ppm}$ for 4-Ph-SBF and $6.73 \mathrm{ppm}$ for 4-PhCz-SBF).
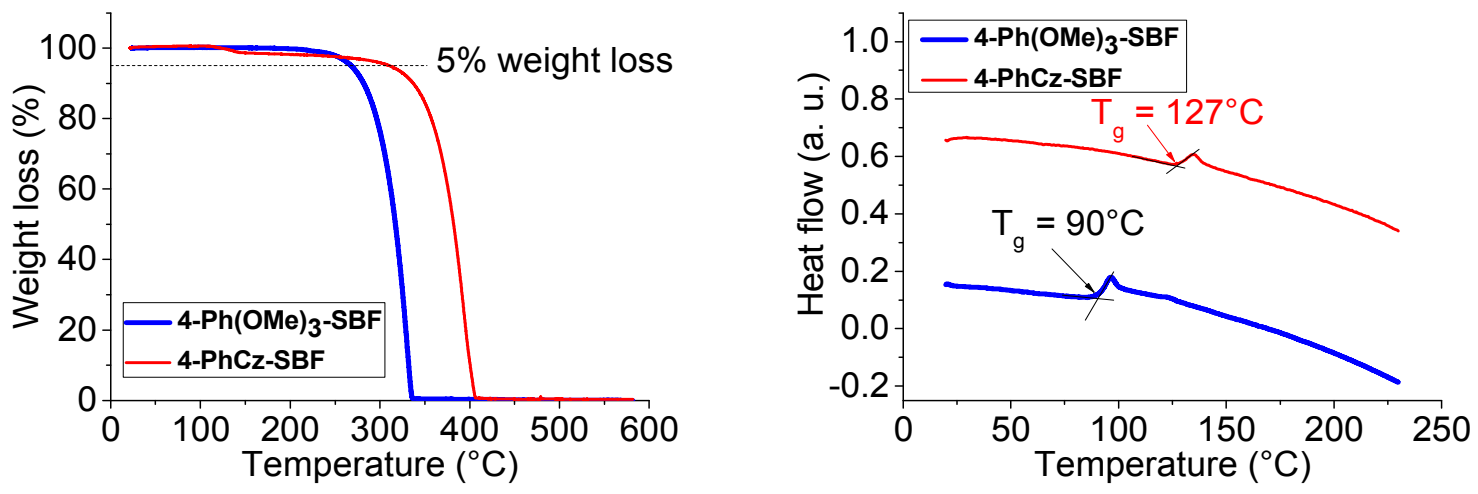

Figure 1. TGA (left) and DSC curves (right) of 4-Ph(OMe) ${ }_{3}-\mathbf{S B F}$ (blue line) and of 4-PhCzSBF (red line). 
The thermal properties of 4-Ph(OMe) $)_{3}-\mathbf{S B F}$ and of 4-PhCz-SBF were investigated by thermogravimetric analysis (TGA, figure 1 left) and differential scanning calorimetry (DSC, figure 1 right). The decomposition temperatures, $\mathrm{T}_{\mathrm{d}}$, corresponding to $5 \%$ mass loss were recorded at $268^{\circ} \mathrm{C}$ for $\mathbf{4 - P h}(\mathbf{O M e})_{3}$-SBF and at $311^{\circ} \mathrm{C}$ for $\mathbf{4 - P h C z - S B F}$. The two compounds appear therefore more stable than their constituted building blocks SBF $\left(\mathrm{T}_{\mathrm{d}}: 234^{\circ} \mathrm{C}\right)$ and 4-Ph-SBF $\left(\mathrm{T}_{\mathrm{d}}: 254^{\circ} \mathrm{C}\right)^{28}$ and also more stable than other SBF compounds substituted in position 4 with pyridine isomers $\left(\mathrm{T}_{\mathrm{d}}\right.$ between 217 and $\left.242^{\circ} \mathrm{C}\right) .{ }^{32}$ Moreover, as the mass loss appears total around $340^{\circ} \mathrm{C}$ for $4-\mathbf{P h}(\mathbf{O M e})_{3}-\mathbf{S B F}$ and around $410^{\circ} \mathrm{C}$ for $\mathbf{4 - P h C z - S B F}$, we believe that the sublimation occurs at these temperatures without a real decomposition of the compounds. ${ }^{36}$

DSC measurements were performed for the two dyes between 20 to $230^{\circ} \mathrm{C}$. At the first heating curve (see SI), the two compounds present a sharp endothermic peak at $223^{\circ} \mathrm{C}\left(\mathbf{4 - P h}(\mathbf{O M e})_{3^{-}}\right.$ SBF) and at $206^{\circ} \mathrm{C}$ (4-PhCz-SBF), associated with the melting of the two compounds ( $\mathrm{T}_{\mathrm{m}}: 215$ and $200^{\circ} \mathrm{C}$ respectively from the peak onset). When both liquids were cooled down at the same rate from 230 to $20^{\circ} \mathrm{C}$, no recrystallization occurs and the cooling leads to amorphous solids. At the second heating curve (figure 1, right), a glass transition phenomenon was observed at $100^{\circ} \mathrm{C}$ for 4-Ph(OMe) $)_{3}-\mathbf{S B F}$ and at $135^{\circ} \mathrm{C}$ for 4-PhCz-SBF $\left(\mathrm{T}_{\mathrm{g}}\right.$ : $90^{\circ} \mathrm{C}$ and $127^{\circ} \mathrm{C}$ resp. from the peak onset). As observed above for the $\mathrm{T}_{\mathrm{d}}$, the $\mathrm{T}_{\mathrm{g}}$ of 4-PhCz-SBF appears therefore significantly higher than that of their building blocks SBF and $\mathbf{4 - P h}-\mathbf{S B F} \mathbf{F}^{28}$ and also higher than those of SBFs substituted in $\mathrm{C} 4$ with pyridine and pyrimidine units $\left(\mathrm{T}_{\mathrm{g}}\right.$ of these compounds range between 76 and $\left.92^{\circ} \mathrm{C}\right) .{ }^{32,33}$ Thus, the bulkiness induced by the presence of the phenylcarbazole group leads to excellent thermal properties, key feature for the further device lifetime. The $\mathrm{T}_{\mathrm{g}}$ of 4$\mathbf{P h}(\mathbf{O M e})_{3}-\mathbf{S B F}$ is lower, $90^{\circ} \mathrm{C}$, but remains in the same range than that of the other dyes exposed above. Finally, one can note that, contrary to SBF and 4-Ph-SBF which both present a 
crystallization transition at $\mathrm{T}_{\mathrm{c}}=135^{\circ} \mathrm{C}$ (upon cooling) and at $\mathrm{T}_{\mathrm{c}}=115^{\circ} \mathrm{C}$ (upon heating), ${ }^{28}$ neither 4-Ph(OMe) $)_{3}$-SBF nor 4-PhCz-SBF present any crystallization phenomena whatever the DSC cycles, which is highly beneficial for further devices incorporation.

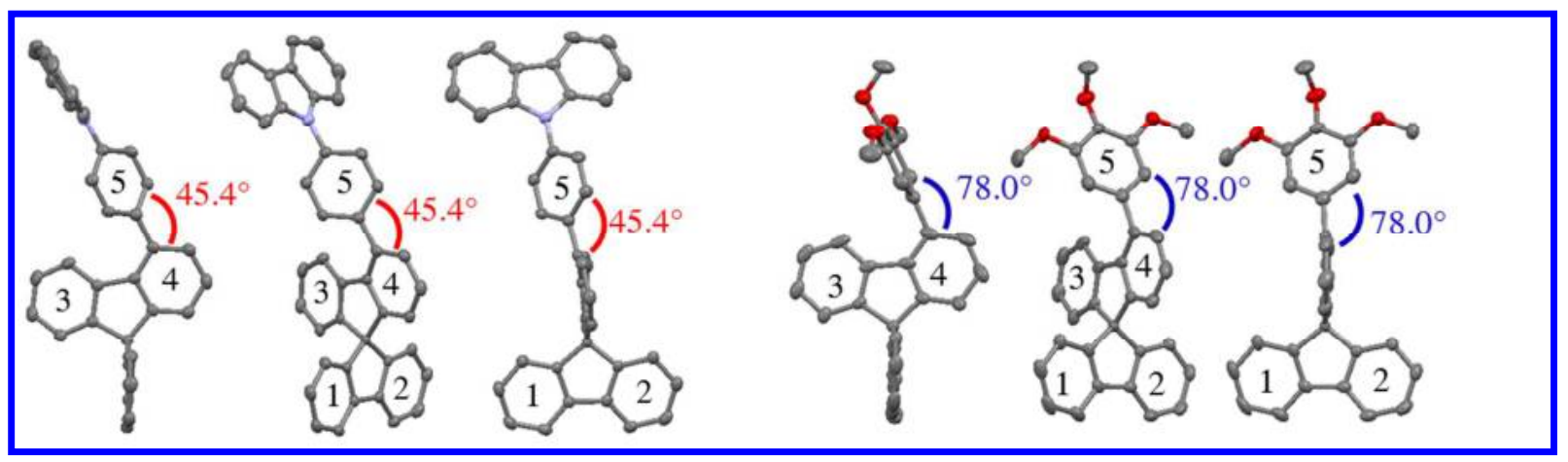

Figure 2. Different views of molecular structures of 4-PhCz-SBF (left) and of 4-Ph(OMe) ${ }_{3}$-SBF (right) obtained by X-Ray diffraction on single crystals

X-Ray data on single crystals of 4-PhCz-SBF and 4-Ph(OMe) $)_{3}-\mathbf{S B F}$ are presented figure 2. Structures of 4-PhCz-SBF and 4-Ph(OMe) $)_{3}-\mathrm{SBF}$, respectively, reveal one molecule in the $\mathrm{P}$ $2 / \mathrm{n}$ and $\mathrm{P} 2{ }_{1} / \mathrm{c}$ space groups, respectively. Several important structural features need to be stressed. First, the angle between the plane of the fluorene and the one of its C4-substituent needs to be evaluated as it drives the electronic coupling between the two fragments. Thus, for 4-PhCz-SBF, an angle of $45.4^{\circ}$ is measured between the pendant phenyl ring (labelled 5) and the substituted phenyl ring of the fluorene (labelled 4), whereas the corresponding angle of 4-Ph(OMe) $)_{3}-\mathrm{SBF}$ is impressively larger, evaluated at $78.0^{\circ}$. Thus, despite a larger substituent attached, 4-PhCz-SBF displays a smaller angle than that of 4-Ph(OMe) ${ }_{3}-\mathbf{S B F}$. This finding indicates that the substitution pattern, i.e. meta/para vs para, of the pendant phenyl ring 5 has a stronger impact on the angle than the bulkiness of the substituent itself. This is an interesting feature to finely control in the future the fluorene-phenyl angle and hence the resulting electronic properties (see below). 
Compared to unsubstituted 4-Ph-SBF (fluorene/phenyl angle was measured at $51.2^{\circ}$ for one molecule and at $56.6^{\circ}$ for the other; two molecules were indeed present in the asymmetric unit), ${ }^{28}$ the fluorene/phenyl angle is slightly smaller for 4-PhCz-SBF and much larger for 4-Ph(OMe $)_{3}$-SBF. As this angle drives the intensity of the $\pi$-conjugation between the fluorene and the substituent, this signs herein a weaker (respectively higher) $\pi$-conjugation breaking between the two $\pi$-systems (fluorene and phenyl) in 4-PhCz-SBF (respectively 4-Ph(OMe) ${ }_{3}$-SBF) than in 4-Ph-SBF.

Another interesting and uncommon structural feature in 4-substituted SBFs is linked to the deformation of the substituted fluorene moiety. Indeed, in the case of 4-PhCz-SBF, one can note a strong deformation of the substituted fluorene core, $11.2^{\circ}$ between rings 3 and 4 , whereas the unsubstituted fluorene presents a small angle between rings 1 and 2 of $4.0^{\circ}$. This is a very rare structural feature as the fluorene moiety due to its ring bridging has most of the time a flat and undistorted structure. This clearly shows the significant impact of the C4-substitution on the folding of the fluorene. ${ }^{45}$ A high value was also reported for 4-Ph-SBF with an angle between ring 3 and ring 4 as high as $12.7^{\circ} .{ }^{28}$ However, it is important to mention that it remains difficult to perfectly rationalize these structural deformations since the substituted fluorene of 4-Ph(OMe) 3 $_{3}$ SBF is almost flat (angle between ring 3 and ring 4 of $2.7^{\circ}$ almost identical to that of its non-substituted fluorene, i.e. $3.2^{\circ}$ ). This feature may be assigned to the different intermolecular packing observed for the two molecules (See SI). Indeed, in the packing diagram of 4-PhCz-SBF, short $\mathrm{C} / \mathrm{C}$ intermolecular distances are observed $(\mathrm{dC} / \mathrm{C}=3.28$ and $3.32 \AA$, see SI) between carbazole units and the unsubstituted fluorene unit (rings labeled 1 and 2). These distances are shorter than the sum of the van der Waals radii ${ }^{46}$ and translate significant intermolecular interactions between 4-PhCz-SBF molecules in the solid state. In addition, some 
short $\mathrm{C} / \mathrm{H}$ intermolecular distances are also detected $(\mathrm{dC} / \mathrm{H}=2.84-2.89 \AA$, see SI), being slightly shorter than the sum of the van der Waals radii. ${ }^{46}$ However, in the case of $4-\mathbf{P h}(\mathbf{O M e})_{3}-\mathbf{S B F}$, no short $\mathrm{C} / \mathrm{C}$ intermolecular contacts are observed in the packing diagram and only some short $\mathrm{C} / \mathrm{H}$ intermolecular distances $(\mathrm{dC} / \mathrm{H}=2.64-2.88 \AA$, see $\mathrm{SI})$ between the fluorene units are detected. Finally, some short $\mathrm{H} / \mathrm{H}$ and $\mathrm{O} / \mathrm{H}$ intermolecular distances have also been measured $(\mathrm{dH} / \mathrm{H}=2.28 \AA, \mathrm{dO} / \mathrm{H}=2.63 \AA$, see $\mathrm{SI})$. Thus, the very different molecular packing of the two compounds leads to different structural features such as the deformation of the fluorene and will also have interesting electronic consequences (See solid sate emission below)
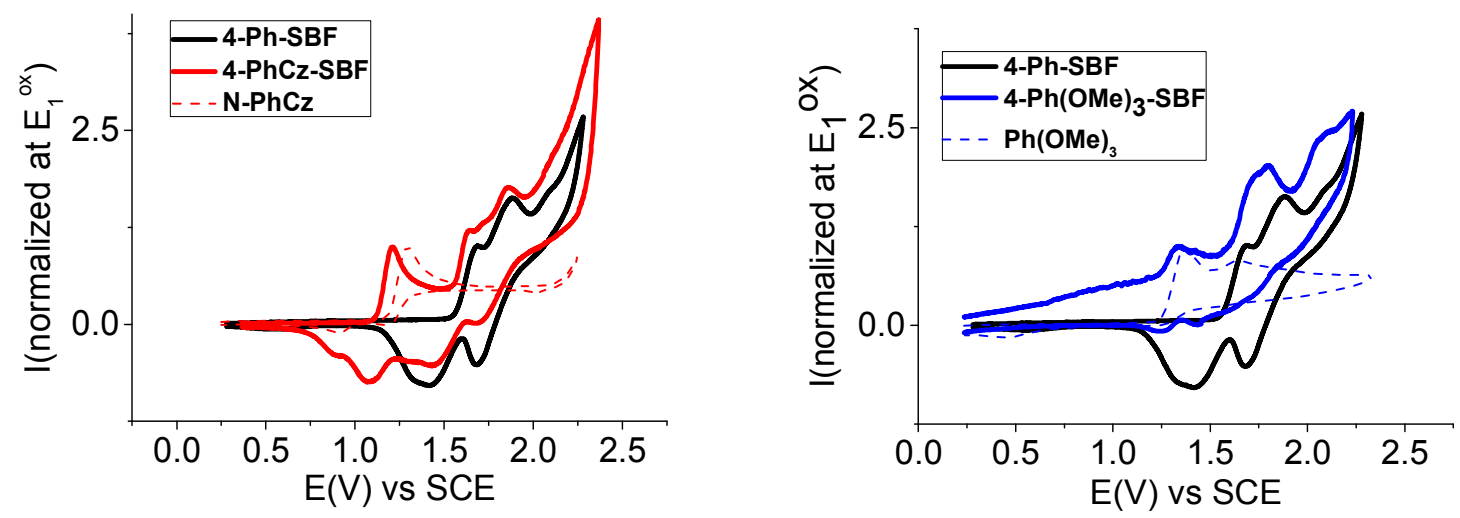

Figure 3. Cyclic voltammetry at $100 \mathrm{mVs}^{-1}$ in $\mathrm{CH}_{2} \mathrm{Cl}_{2} /\left[\mathrm{NBu}_{4}\right]\left[\mathrm{PF}_{6}\right] 0.2 \mathrm{M}$ in the presence of 4-Ph-SBF (black line), 4-PhCz-SBF (red line), N-PhCz (red dotted line), 4-Ph(OMe)3-SBF (blue line) and $\mathbf{P h}(\mathbf{O M e})_{3}$ (blue dotted line).

Electrochemical properties of the two compounds have been investigated by cyclic voltammetry $(\mathrm{CV})$ recorded in $\mathrm{CH}_{2} \mathrm{Cl}_{2}$ both in reduction and in oxidation. Their electronic properties were compared to those (i) of 4-Ph-SBF to shed light on the effect of electron donating fragments (methoxy and carbazole) and (ii) of their constituted building blocks, $N$-phenylcarbazole $(\mathbf{N}-\mathbf{P h C z})$ for $\mathbf{4 - P h C z - S B F}$ and 1,2,3-trimethoxybenzene $\left(\mathbf{P h}(\mathbf{O M e})_{3}\right)$ for 4-Ph(OMe $)_{3}-\mathrm{SBF}$ in order to investigate the effect of their incorporation on the SBF core. 
First, in reduction (figures in SI), no wave was detected in dichloromethane and the LUMO energy levels of the two compounds were determined from the onset reduction potentials at $-1.97 \mathrm{eV}$ for $\mathbf{4 - P h C z - S B F}$ and at $-1.91 \mathrm{eV}$ for $\mathbf{4 - P h}(\mathbf{O M e})_{3} \mathbf{- S B F}$, that means close to the LUMO of 4-Ph-SBF $(-1.95) .{ }^{47^{*}}$ Thus, compared to $4-\mathbf{P h}-\mathbf{S B F}$ one can note that the onset potential of 4-Ph(OMe) $)_{3}-\mathbf{S B F}$ is slightly lower and that of 4-PhCz-SBF significantly higher. This in accordance with the theoretical calculations presented below (figure 5), which show for 4-Ph(OMe $)_{3}$-SBF a weak contribution of the phenyl ring in the LUMO distribution due to the large fluorene/phenyl angle and a strong contribution of the phenyl ring for both 4-PhCz-SBF and 4-Ph-SBF due to the small fluorene/phenyl angle. Thus, electrochemical measurements and theoretical calculations show the same trend for the LUMO energy levels of the three compounds: 4-PhCz-SBF LUMO level $<$ 4-Ph-SBF LUMO level $<$ 4-Ph(OMe) ${ }_{3}$-SBF LUMO level (LUMO levels are respectively calculated in vacuum at $-0.64,-0.47$ and $-0.46 \mathrm{eV}$, see SI).

In oxidation, both compounds present successive oxidation waves with peak potentials at 1.21, 1.64, 1.86 V for 4-PhCz-SBF (figure 3-left, red line) and at 1.33, 1.72/1.80 (very close waves), $2.1 \mathrm{~V}$ for 4-Ph(OMe)$)_{3}$-SBF (figure 3-right, blue line). Compared to 4-Ph-SBF, which first oxidation is centred at $1.68 \mathrm{~V}$ (figure 3, black line), both 4-PhCz-SBF and 4-Ph(OMe) $)_{3}-\mathbf{S B F}$ are clearly more easily oxidized. Furthermore, compared to the oxidation of their respective donor fragment, $\mathbf{N}-\mathbf{P h C z}$ (figure 3-left, red dotted line) and $\mathbf{P h}(\mathbf{O M e})_{3}$ (figure 3-right, blue dotted line), the first oxidation of 4-PhCz-SBF and 4-Ph(OMe) ${ }_{3}-\mathrm{SBF}$ is slightly shifted to less anodic values $\left(\mathrm{E}_{\text {ox }}^{1}: 1.21 \mathrm{~V}\right.$ vs $1.29 \mathrm{~V}$ for 4-PhCz-SBF $v s \mathrm{~N}-\mathbf{P h C z}$ and $\mathrm{E}_{\text {ox }}^{1}: 1.33 \mathrm{~V}$ vs $1.37 \mathrm{~V}$ for 4-

\footnotetext{
* It should be mentioned that, in DMF, well defined waves are obtained (see SI) with peak potentials recorded at $-2.44 \mathrm{~V}$ for $\mathbf{4 - P h C z - S B F}$ (LUMO: $-2.10 \mathrm{eV}$ ), $-2.55 \mathrm{~V}$ for $\mathbf{4 - P h - S B F}$

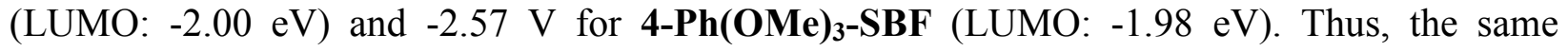
potentials trend is obtained (see $\mathrm{SI}$ ) both in DMF and in $\mathrm{CH}_{2} \mathrm{Cl}_{2}$.
} 


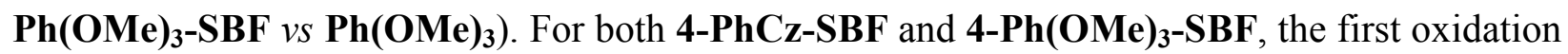
is therefore assigned to the oxidation of the corresponding electron-rich moieties with a different influence of the spirofluorene core due to the different conjugation disruption. Thus, 4-Ph(OMe) $)_{3}$-SBF is only shifted by $40 \mathrm{mV}$ compared to $\mathbf{P h}(\mathbf{O M e})_{3}$ whereas $\mathbf{4 - P h C z - S B F}$ is anodically shifted by $80 \mathrm{mV}$ compared to its constituted unit N-PhCz. This difference can be again correlated to the fluorene/phenyl angle which is strongly larger in the case of $4-\mathbf{P h}(\mathbf{O M e})_{\mathbf{3}^{-}}$ SBF $\left(78.0^{\circ}\right)$ than in the case of $4-\mathbf{P h C z - S B F}\left(45.4^{\circ}\right)$, therefore inducing a more intense conjugation disruption between the fluorene and the pendant phenyl for the former.

The second and third oxidations occur at 1.64, $1.86 \mathrm{~V}$ for 4-PhCz-SBF and at 1.72/1.80 V for 4-Ph(OMe $)_{3}-\mathbf{S B F}$, that means in the same potential range than the two successive oxidations of 4-Ph-SBF $(1.68$ and $1.88 \mathrm{~V})$ and have been assigned to the oxidation of the fluorene units. ${ }^{2}$ Additionally, differential pulse voltammetry (DPV, see figure in SI) recorded for each compound

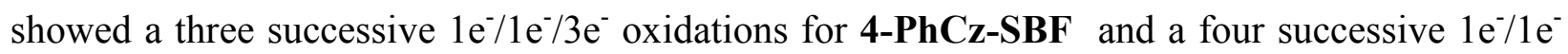
$/ 1 \mathrm{e}^{-} / 2 \mathrm{e}^{-}$oxidation process for $4-\mathbf{P h}(\mathbf{O M e})_{3}-\mathbf{S B F}$. Reaching the third oxidation process for 4-PhCz-SBF and the fourth one for $\mathbf{P h}(\mathrm{OMe})_{3}$-SBF lead to an electropolymerization process, observed along successive CVs by the appearance and regular increase of new redox processes (see figures in SI) and by the coating of the electrode surface by insoluble electroactive deposits. The electrodeposition process, classically observed along oxidation of SBF derivatives, is assigned to carbon-carbon coupling at the $\mathrm{C} 2-\mathrm{C} 7$ and $\mathrm{C} 2$ '-C7' carbon atoms of the SBF units. ${ }^{2}$, ${ }^{48-51}$ As no polymerization process was observed by oxidation of $\mathbf{P h}(\mathbf{O M e})_{3}$, the electrochemical behaviour of the polymer obtained by anodic oxidation of $4-\mathbf{P h}(\mathbf{O M e})_{3}-\mathbf{S B F}$ is very similar to that of poly(4-Ph-SBF), both polymers possessing a HOMO level close to $-5.5 \mathrm{eV}$ (see figure in SI). Contrariwise, as the anodic oxidation of $\mathbf{N}-\mathbf{P h C z}$ at potential more positive than $2.2 \mathrm{~V} v s$ 
SCE leads to the formation of an electroactive polymer (see figure in SI), the phenyl/carbazole core is also surely involved in the electropolymerization process of 4-PhCz-SBF. The HOMO energy level of the corresponding polymer poly(4-PhCz-SBF) lye between that of poly(NPhCz), $-5.25 \mathrm{eV}$, and that of poly(SBF), $-5.57 \mathrm{eV} \cdot{ }^{28} \mathrm{~A}$ comparison of the electrochemical behaviour of the polymers is presented in SI.

The HOMO energy levels of 4-PhCz-SBF and 4-Ph(OMe) $)_{3}-\mathbf{S B F}$ determined from the onset potential of their first oxidation (1.12 and $1.22 \mathrm{~V}$ respectively) lye at $-5.52 \mathrm{eV}$ and $-5.62 \mathrm{eV}$, respectively. Those HOMO energy levels are very close to those of their corresponding electron donating fragment, N-PhCz $(-5.59 \mathrm{eV})$ and $\mathbf{P h}(\mathbf{O M e})_{\mathbf{3}}(-5.67 \mathrm{eV})$, confirming the key importance of these fragments on the HOMO energies. However, and as above mentioned, the C4 substituted fluorene has a non-negligible influence on the HOMO energy levels as the conjugation is not completely broken. In addition, the HOMO energy levels of both 4-PhCz-SBF and 4-Ph(OMe) $)_{3}$-SBF lye ca 0.3/0.45 eV higher than that of 4-Ph-SBF (-5.95 eV) due the electron-rich character of the carbazole or the methoxy group. Thus, due to the conjugation disruption at the $\mathrm{C} 4$ position of $\mathbf{S B F}$, the electrochemical data indicate that HOMOs are mainly governed by the electron-rich building blocks with nevertheless an influence of the SBF core. In case of 4-PhCz-SBF, this fact is clearly confirmed by molecular modelling. Indeed, the HOMO of 4-PhCz-SBF is almost exclusively spread out on the $N$-phenylcarbazole fragment (figure 5-left) whereas that of 4-Ph-SBF on the SBF core (figure 5-right). 4-Ph(OMe) ${ }_{3}-\mathbf{S B F}$ seems to be an intermediate case, with its $\mathrm{HOMO}$ delocalized both on $\mathrm{SBF}$ and $\mathrm{Ph}(\mathrm{OMe})_{3}$ moieties (figure 5-middle). Depending on both the strength of the donor group and the fluorene/phenyl angle, the HOMO (energy and shape) can hence be more or less governed by the electron donating fragment. This particularity appears very interesting to finely tune the 
electronic properties of 4-substituted SBFs. Finally, the electrochemical energy gaps $\Delta \mathrm{E}^{\mathrm{el}}$ of 4-PhCz-SBF and 4-Ph(OMe) $)_{3}$-SBF are respectively evaluated at $3.55 \mathrm{eV}$ and at $3.71 \mathrm{eV}$ for 4-Ph(OMe) $)_{3}-\mathbf{S B F}$, being shorter than that of 4-Ph-SBF $(4.0 \mathrm{eV})$ due to their strong increase of the HOMO energy level without significant modification of the LUMO energy levels.

Table 1. Electrochemical and spectroscopic properties of $4-\mathbf{P h C z}-\mathbf{S B F}$ and $4-\mathbf{P h}(\mathbf{O M e})_{3}-\mathbf{S B F}$.

\begin{tabular}{|c|c|c|c|}
\hline & & 4-PhCz-SBF & 4-Ph(OMe $)_{3}-\mathrm{SBF}$ \\
\hline \multirow{6}{*}{ 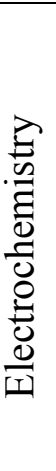 } & Oxidation peaks (V) & $1.21,1.64,1.86$ & $1.33,1.72,1.80,2.1$ \\
\hline & $\mathrm{E}_{\text {onset }}^{\text {ox }}(\mathrm{V})$ & 1.12 & 1.22 \\
\hline & $\mathrm{HOMO}(\mathrm{eV})$ & -5.52 & -5.62 \\
\hline & $\mathrm{E}_{\text {onset }}{ }^{\text {red }}(\mathrm{V})$ & -2.43 & -2.49 \\
\hline & LUMO (eV) & -1.97 & -1.91 \\
\hline & $\Delta \mathrm{E}^{\text {elec }}(\mathrm{eV})$ & 3.55 & 3.71 \\
\hline \multirow{12}{*}{ 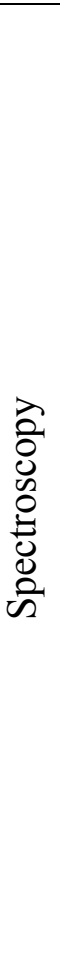 } & $\lambda_{\mathrm{abs}}(\mathrm{nm})^{\mathrm{a}}$ & $293,309,325(\mathrm{sh}), 340$ & 297,309 \\
\hline & $\varepsilon\left(10^{4} \mathrm{~L} \cdot \mathrm{mol}^{-1} \cdot \mathrm{m}^{-2}\right)^{\mathrm{a}}$ & $3.7,2.8,1.0,0.7$ & $1.0,1.7$ \\
\hline & $\Delta \mathrm{E}^{\mathrm{opt}}(\mathrm{eV})^{\mathrm{g}}$ & 3.58 & 3.82 \\
\hline & $\lambda_{\text {em-liq }}(\mathrm{nm})^{\mathrm{a}}$ & 345,361 & 375 \\
\hline & $\phi(\%)^{b}$ & 54 & 60 \\
\hline & $\lambda_{\text {em-film }}$ & 378 & 378 \\
\hline & $\tau(\mathrm{ns})^{\mathrm{c}}$ & 4.01 & 2.84 \\
\hline & $\mathrm{k}_{\mathrm{r}}\left(\mathrm{s}^{-1}\right)^{\mathrm{c}}$ & $1.2 \times 10^{8}$ & $2.1 \times 10^{8}$ \\
\hline & $\mathrm{k}_{\mathrm{nr}}\left(\mathrm{s}^{-1}\right)^{\mathrm{c}}$ & $1.2 \times 10^{8}$ & $1.4 \times 10^{8}$ \\
\hline & $\lambda_{\text {phospho }}(\mathrm{nm})^{\mathrm{d}}$ & $442,473^{f}$ & $437,453,466$ \\
\hline & $\mathrm{E}_{\mathrm{T}}(\mathrm{eV})^{\mathrm{e}}$ & 2.81 & 2.84 \\
\hline & $\tau(\mathrm{s})^{\mathrm{h}}$ & 4.0 & 4.6 \\
\hline
\end{tabular}

a. in cyclohexane. b. Calculated from a quinine sulfate solution in $1 \mathrm{~N}$ sulfuric acid solution. c. $\lambda_{\text {exc }}=375 \mathrm{~nm}, \mathrm{k}_{\mathrm{r}}=\phi / \tau$ and $\mathrm{k}_{\mathrm{nr}}=(1 / \tau) \times(1-\phi)$ d. in 2-methyl-THF. e. $\mathrm{E}_{\mathrm{T}}=1239.84 / \lambda$ (in nm), f. It 
should be mentioned that two other bands at higher energies (at ca 407, $421 \mathrm{~nm}$ ) were detected for 4-PhCz-SBF, assigned through decay curves to fluorescence contributions, $g$. from the onset of the last band in cyclohexane, h. $\lambda_{\text {exc }}=312 \mathrm{~nm}$

The UV-vis absorption spectra of the two compounds recorded in cyclohexane are presented figure 4 (left). Both compounds present the same absorption band with a maximum at $309 \mathrm{~nm}$ (molar absorption coefficient is higher in the case of 4-PhCz-SBF) similar to the main absorption band of SBF and of 4-Ph-SBF. Hence, this band is due to transitions occurring on the SBF unit. For 4-Ph(OMe) $)_{3}-\mathbf{S B F}$ and 4-Ph-SBF, the contribution at $309 \mathrm{~nm}$ presents the same wavelength tail at lower energy, leading to an optical gap $\Delta \mathrm{E}^{\mathrm{opt}}$ determined from the onset of the absorption band of $3.82 \mathrm{eV}$. This tail translates a certain degree of conjugation between the fluorene and its C4-substituent and it has been recently shown that it is possible to modify its intensity by the nature of the substituent borne by the fluorene. Indeed, with pyridine isomers attached (chart 1), this tail displays different intensities translating more or less longer $\pi$ conjugated pathways. ${ }^{32}$ In the present case, the intensity of the tail (and hence the $\pi$-conjugation between the phenyl and the fluorene) is almost identical between 4-Ph-SBF and 4-Ph(OMe) $)_{3}-\mathbf{S B F}$ clearly showing that the trimethoxy units have a very weak influence on the absorption spectrum. This conjugation effect cannot be explored in the case of $\mathbf{4 - P h C z - S B F}$ because of the presence of (i) a shoulder at $325 \mathrm{~nm}$ and of (ii) an additional band at $340 \mathrm{~nm}$. The comparison of the spectrum of 4-PhCz-SBF and the sum of spectra of each unit 4-Ph-SBF and N-PhCz (figure 4, right) shows a significant difference in the domain 295-330 nm. Indeed, in that domain, 4-PhCz-SBF displays higher absorption molar coefficients than the sum of its building blocks. This feature indicates that the absorption of 4-PhCz-SBF in the 295-330 nm range is not only due to the sum of the absorption of 4-PhCz-SBF and N-PhCz but is also induced by the interactions between these two units. Thus, a charge transfer band between the $N$ - 
phenylcarbazole and phenyl-substituted SBF units is responsible of absorption in the 295-330 nm range leading to the shoulder at $325 \mathrm{~nm}$ and to the higher intensity of the band at $309 \mathrm{~nm}$. Regarding the band at $340 \mathrm{~nm}$, the difference between the spectrum of 4-PhCz-SBF and the sum of the spectra of each constituted unit remains weak (figure 5, right). It should be noted that 4Ph-SBF has no absorption in this range whereas the absorption spectrum of $\mathbf{N}-\mathbf{P h C z}$ (see SI) consists of three bands in the 290-350 nm range with maxima at 292, 327 and $339 \mathrm{~nm}$. This comparison allows assigning for $\mathbf{4 - P h C z - S B F}$ the band at $340 \mathrm{~nm}$ to the absorption of the $N$ phenylcarbazole fragment. The optical gap $\Delta \mathrm{E}^{\text {opt }}$ of 4-PhCz-SBF, $3.58 \mathrm{eV}$, has been determined from the onset of the absorption band at $340 \mathrm{~nm}$.

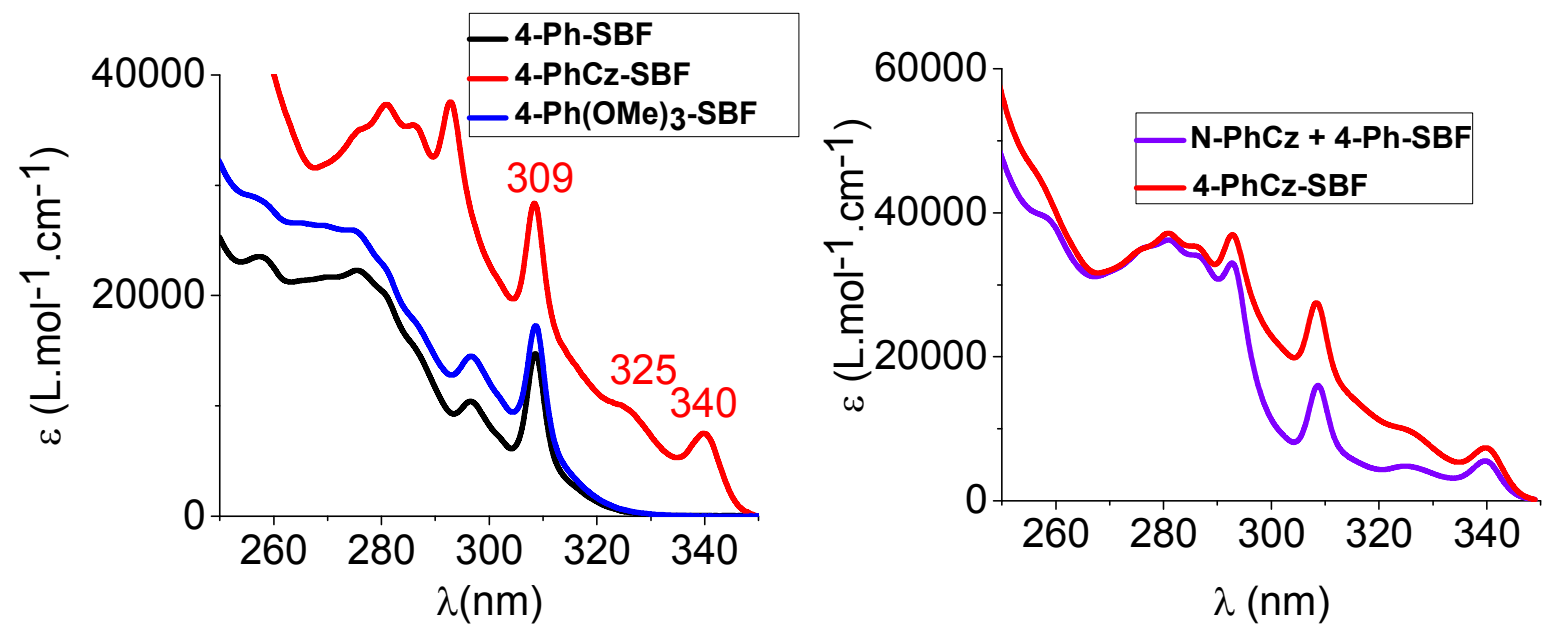

Figure 4. Absorption spectra of 4-Ph-SBF (black), 4-PhCz-SBF (red), 4-Ph(OMe) ${ }_{3}$-SBF (blue) and the sum of the absorption spectra of N-PhCz and 4-Ph-SBF (purple) in cyclohexane

In order to shed light on the origin of these bands, time-dependant density functional theory (TD-DFT) calculations have been performed with the $6-311+\mathrm{g}(\mathrm{d}, \mathrm{p})$ basis set using four different hybrid exchange-correlation functionals: B3LYP, PBE0, CAM-B3LYP and M06-2X. The B3LYP and PBE0 levels of theory give best matches in terms of wavelength range compared to CAM-B3LYP and M06-2X when looking at the band experimentally found at $309 \mathrm{~nm}$ (Table 2). 
For all functionals, this band experimentally found at $309 \mathrm{~nm}$ is due to two transitions $\left(\lambda_{1}\right.$ and $\lambda_{2}$, Table 2)

Table 2. Calculated wavelengths corresponding to the band at $309 \mathrm{~nm}$ for 4-PhCz-SBF and 4-Ph(OMe) $)_{3}$-SBF using the four different hybrid exchange-correlation functionals: B3LYP, PBE0, CAM-B3LYP and M06-2X

\begin{tabular}{|l|l|l|l|l|l|}
\cline { 3 - 6 } \multicolumn{2}{c|}{} & B3LYP & PBE0 & CAM-B3LYP & M06-2X \\
\hline \multirow{2}{*}{ 4-PhCz-SBF } & $\lambda_{1}(\mathrm{~nm})$ & 304 & 295 & 267 & 268 \\
\cline { 3 - 6 } & $\lambda_{2}(\mathrm{~nm})$ & 293 & 284 & 265 & 263 \\
\hline \multirow{4}{*}{ 4-Ph(OMe) } & & & & & 267 \\
\cline { 3 - 6 } & $\lambda_{1}(\mathrm{~nm})$ & 299 & 289 & 268 & 264 \\
\cline { 2 - 6 } & $\lambda_{2}(\mathrm{~nm})$ & 297 & 286 & 265 & \\
\hline
\end{tabular}

However, the charge transfer transition, experimentally found at $325 \mathrm{~nm}$, is not well modelized by the B3LYP and PBE0 functionals. Indeed, according to the TD-DFT calculations obtained with these functionals, the charge transfer transition is found at a higher wavelength than the transition localized on the phenylcarbazole unit (experimentally found at $340 \mathrm{~nm}$ ). By contrast, CAM-B3LYP and M06-2X functionals modelize a charge transfer transition at a lower wavelength than the transition localized on the phenylcarbazole unit. This finding is in agreement with what we experimentally observed as previously discussed (i.e. a charge transfer shoulder at $325 \mathrm{~nm}$ and a band at $340 \mathrm{~nm}$ localized on the phenylcarbazole part). For this reason, TD-DFT diagram (figure 5) obtained by M06-2X level of theory is shown despite the fact that the calculated transitions are underestimated by $50 \mathrm{~nm}$. 


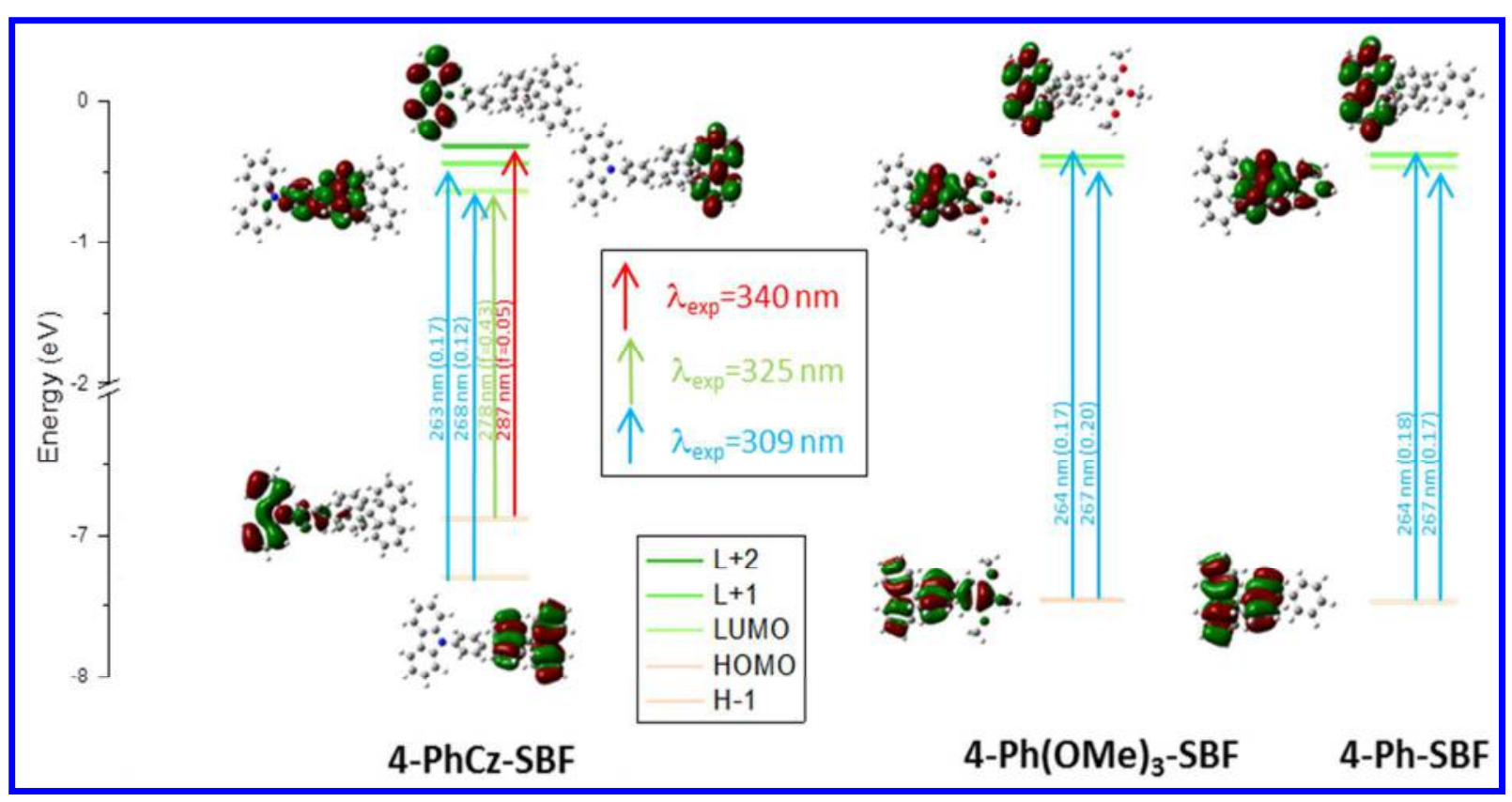

Figure 5. Representation of the energy levels and the main molecular orbitals involved in the electronic transitions of 4-PhCz-SBF (left), 4-Ph(OMe) ${ }_{3}-\mathbf{S B F}$ (middle) and 4-Ph-SBF (right) obtained by TD-DFT M06-2X/6-311+G(d,p), shown with an isovalue of $0.04\left[\mathrm{e} \mathrm{bohr}{ }^{-3}\right]^{1 / 2}$. For clarity purpose, only the main contribution of each transition is shown (see SI for details).

In the case of $4-P h(O M e)_{3}-\mathbf{S B F}$, the HOMO is delocalized on the whole molecule (high coefficients on the SBF unit and weak coefficients on the C4 substituent). It is thus similar to the HOMO of 4-Ph-SBF (delocalized on the SBF part, figure 5 right), with a small influence of the methoxy groups. The corresponding orbital delocalized on the SBF core in the case of 4-PhCzSBF is the H-1 orbital, since the HOMO is localized on the phenylcarbazole moiety. The LUMO of both compounds are delocalized on the $\mathrm{C} 4$ substituted fluorene unit and on the pendant phenyl ring, similarly to 4-Ph-SBF. Likewise, the $\mathrm{L}+1$ orbitals of the three compounds are delocalized on the non-substituted fluorene unit. A last orbital plays an important role in the case of 4-PhCzSBF, that is the $\mathrm{L}+2$ orbital which is fully delocalized on the carbazole unit. 
The main absorption band of $\mathbf{4 - P h}(\mathbf{O M e})_{3} \mathbf{- S B F}$, observed at $309 \mathrm{~nm}$, has been attributed to two $\pi-\pi^{*}$ transitions, both from the HOMO (delocalized on the whole molecule) to the LUMO (delocalized on the phenyl-fluorene unit) and $\mathrm{L}+1$ orbital (delocalized on the unsubstituted fluorene unit). 4-PhCz-SBF displays the same band at $309 \mathrm{~nm}$, which is due to the similar two $\pi-\pi^{*}$ transitions: both from the H-1 orbital (delocalized on the SBF core) to the LUMO (delocalized on the phenyl-fluorene unit) and to the $\mathrm{L}+1$ orbital (delocalized on the unsubstituted fluorene unit). The attributions for both molecules are in perfect agreement with the previous observation of a band due to transitions occurring on the SBF unit.

The shoulder at $325 \mathrm{~nm}$ of 4-PhCz-SBF is due to a transition from the HOMO (delocalized on the phenylcarbazole unit) to the LUMO (delocalized on the phenyl-fluorene unit) in accordance with the previous hypothesis stating a band with a significant charge transfer character.

The band at $340 \mathrm{~nm}$ of 4-PhCz-SBF is due to a transition from the HOMO to the L+2 orbital, both localized on the phenylcarbazole unit, as expected by the presence of this band in the absorption spectrum of its constituted building block N-PhCz. The apparent paradox of a higher energy for the $\mathrm{HOMO} \rightarrow \mathrm{LUMO}$ transition than for $\mathrm{HOMO} \rightarrow \mathrm{L}+2$ transition is due to an inversion of the energy levels of the locally excited state and the charge transfer excited state during the structural reorganizations of the excited states from the ground state geometry to the corresponding relaxed geometries (see details in SI).

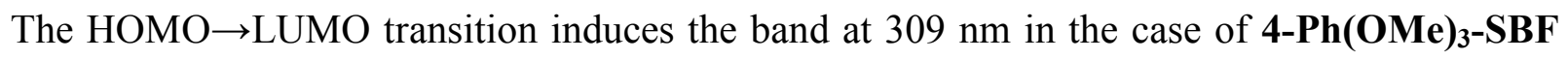
and the band at $325 \mathrm{~nm}$ in the case of 4-PhCz-SBF. Finally, the optical gaps $\Delta \mathrm{E}^{\text {opt }}$ of 4$\mathbf{P h}(\mathrm{OMe})_{3}$-SBF and 4-PhCz-SBF respectively give us an evaluation of the difference between the $\mathrm{HOMO} / \mathrm{LUMO}$ and $\mathrm{HOMO} / \mathrm{L}+2$ orbitals respectively since these transitions are responsible of the bands localized at low energy. Therefore the optical energy gap modulation between the 
two compounds is $0.23 \mathrm{eV}$ larger than the modulation between the energy gap obtained from electrochemical measurements $(0.10 \mathrm{eV})$, which involve HOMO and LUMO.
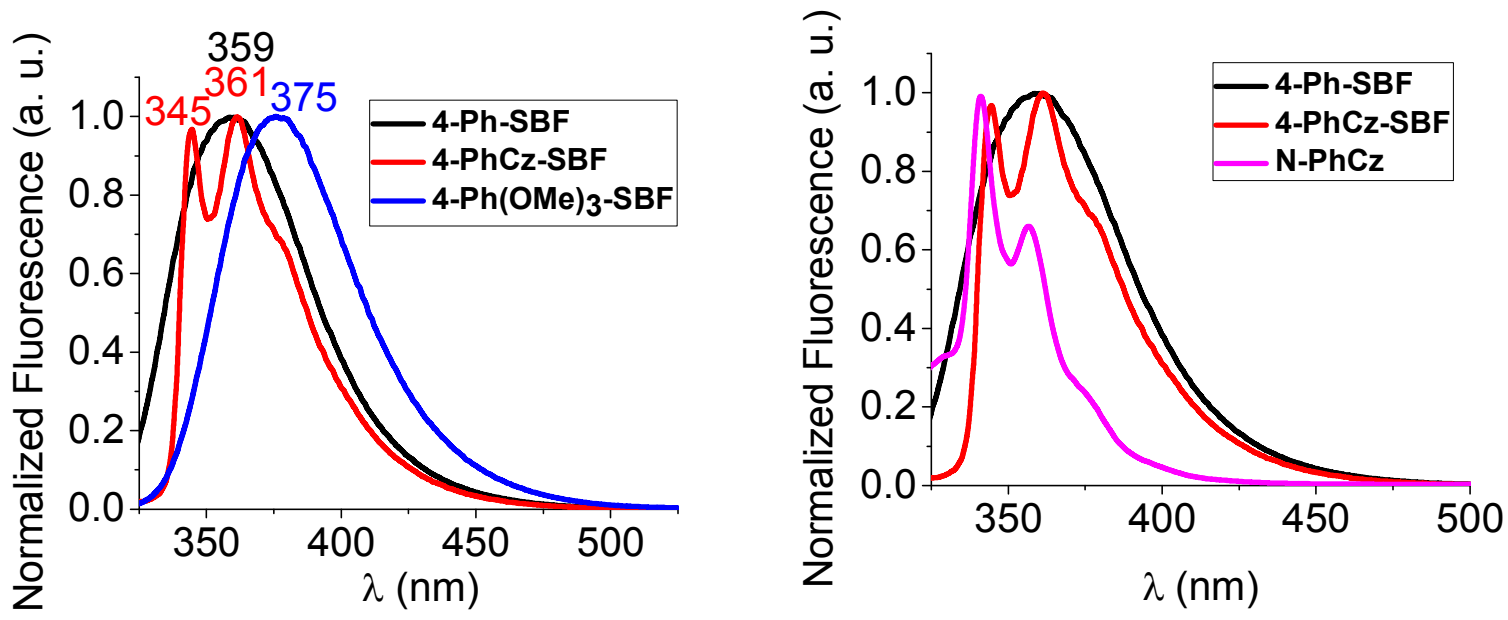

Figure 6. Normalized emission spectra of 4-Ph-SBF (black, $\lambda_{\text {exc }}=309 \mathrm{~nm}$ ), 4-PhCz-SBF $\left(\lambda_{\text {exc }}=295 \mathrm{~nm} \text {, red), 4-Ph(OMe) }\right)_{3}$-SBF (blue, $\left.\lambda_{\text {exc }}=309 \mathrm{~nm}\right)$ and N-PhCz (pink, $\left.\lambda_{\text {exc }}=280 \mathrm{~nm}\right)$ recorded in cyclohexane, $\mathrm{A}\left(\lambda_{\text {exc }}\right)<0.1$

The fluorescence spectra of 4-PhCz-SBF, 4-Ph(OMe) 3 -SBF and 4-Ph-SBF recorded in cyclohexane are presented figure 6 (left). First, the fluorescence spectrum of 4-Ph(OMe $)_{3}-\mathbf{S B F}$ is structureless and large $(\lambda=375 \mathrm{~nm})$ and very similar to those previously reported for other 4-substituted SBFs. ${ }^{28-31,35,52,53}$ In addition, the fluorescence spectrum of 4-Ph(OMe) ${ }_{3}-\mathbf{S B F}$ exacly displays the same shape than that of 4-Ph-SBF but shifted by $17 \mathrm{~nm}(\lambda=359 \mathrm{~nm})$. Thus, both molecules possess a very large Stokes shift, which is one of the characteristics of the uncommon fluorescence of 4-substituted SBFs previously reported but still not understood to date. ${ }^{28-31,35,52,53} \mathrm{We}$ want to provide herein the beginning of an answer. We indeed believe that this large Stokes shift can be explained by the significant differences between the geometries of the ground (S0) and first singlet excited (S1) states observed for both 4-Ph(OMe) ${ }_{3}-\mathbf{S B F}$ (Figure 7-left) and 4-Ph-SBF (Figure 7-right) through theoretical calculations. In addition, one can note 
that the geometry difference between S0 and S1 is more pronounced for $4-\mathbf{P h}(\mathbf{O M e})_{3}-\mathbf{S B F}$ than for 4-Ph-SBF, clearly explaining the difference observed in term of Stokes shift. Furthermore, this low rigidity (allowing an important rearrangement at the excited state) could be the reason of the large and unresolved fluorescence spectra of these two molecules. Thus, we believe that the very unusual fluorescence of 4-subsituted SBFs finds its origin in this strong geometry difference between S0 and S1.

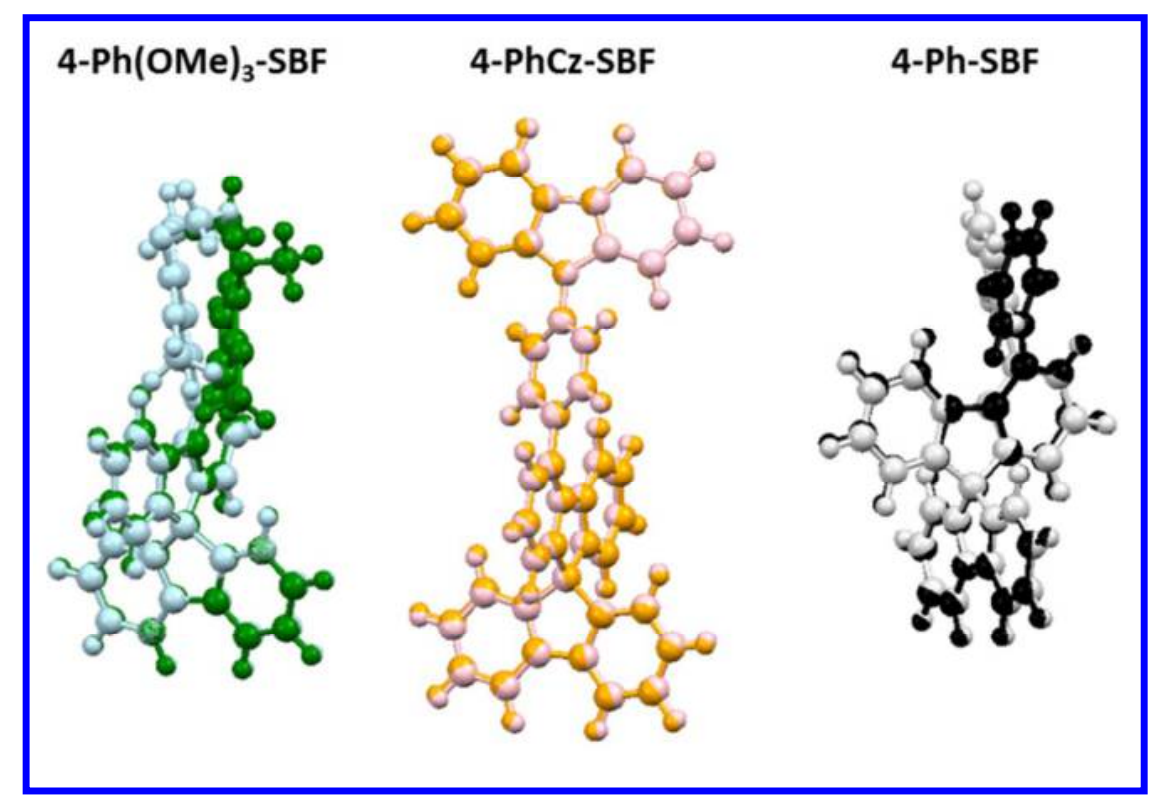

Figure 7. Superposition of the S0 (ground state) and S1 (first singlet excited state) molecular structures obtained by molecular modelling of 4-Ph(OMe) $)_{3}$ SBF (left, S0: sky blue, S1: green), 4-PhCz-SBF (middle, S0: pink, S1: orange) and 4-Ph-SBF (right, S0: grey, S1: black)

4-PhCz-SBF appears as a unique example in the 4-substituted SBFs family reported to date in the literature. Indeed, 4-PhCz-SBF presents a well resolved emission spectrum with maxima at 345,361 and a shoulder at $380 \mathrm{~nm}$. The domain of emission wavelengths is similar to that of 4-Ph-SBF (Figure 6-right). The structured shape is very similar to that of its constituted building block N-PhCz (which emits at $341 \mathrm{~nm}$ with a fine vibronic structure at $357 \mathrm{~nm}$ and a shoulder 
around $375 \mathrm{~nm}$, figure 6-right) but the ratio between the bands is different (1/1 for 4-PhCz-SBF and 3/2 for $\mathbf{N}-\mathbf{P h C z}$ ). In addition, the small Stokes-Shift of $5 \mathrm{~nm}$, calculated from the difference between the lowest energy absorption band $(340 \mathrm{~nm})$ and the highest energy emission band (345 nm), is perfectly explained by the similar geometries of S0 and S1 (figure 7-middle). This is a significant difference with 4-Ph(OMe) $)_{3}-\mathbf{S B F}, \mathbf{4 - P h - S B F}$ and all the 4-substituted SBF reported to date, which explained the different emission spectra of these molecules. Thus, the presence of the pendant carbazole in 4-PhCz-SBF has hence a key role in the peculiar fluorescence of 4-PhCz-SBF, by avoiding strong molecular rearrangements between S0 and S1. Indeed, 4-PhCz-SBF seems to have a high rigidity preventing reorganization at the excited state and this high rigidity could also explain the highly structured fluorescence spectrum compared to the other 4-substituted SBFs and notably 4-Ph(OMe) $)_{3}$-SBF and 4-Ph-SBF presented above. This is to the best of our knowledge the first rationalization of the peculiar fluorescence of this family of dyes.

The quantum yield $\phi$ of $4-\mathbf{P h}(\mathrm{OMe})_{3}$-SBF was calculated in solution at $60 \%$ and that of 4-PhCz-SBF at 54\% (reference : quinine sulphate). Both quantum yields are higher than those of their constituted units $\left(\phi_{4-\mathbf{P h}-\mathbf{S B F}}=40 \%, \phi_{\mathbf{N - P h C z}}=34 \%\right.$ and $\left.\phi_{\mathbf{P h}(\mathbf{O M e}) \mathbf{3}}<1 \%\right)$. It shows the strong impact of the SBF core on the fluorescence quantum yield, especially in the case of 4-Ph(OMe) $)_{3}$-SBF. 

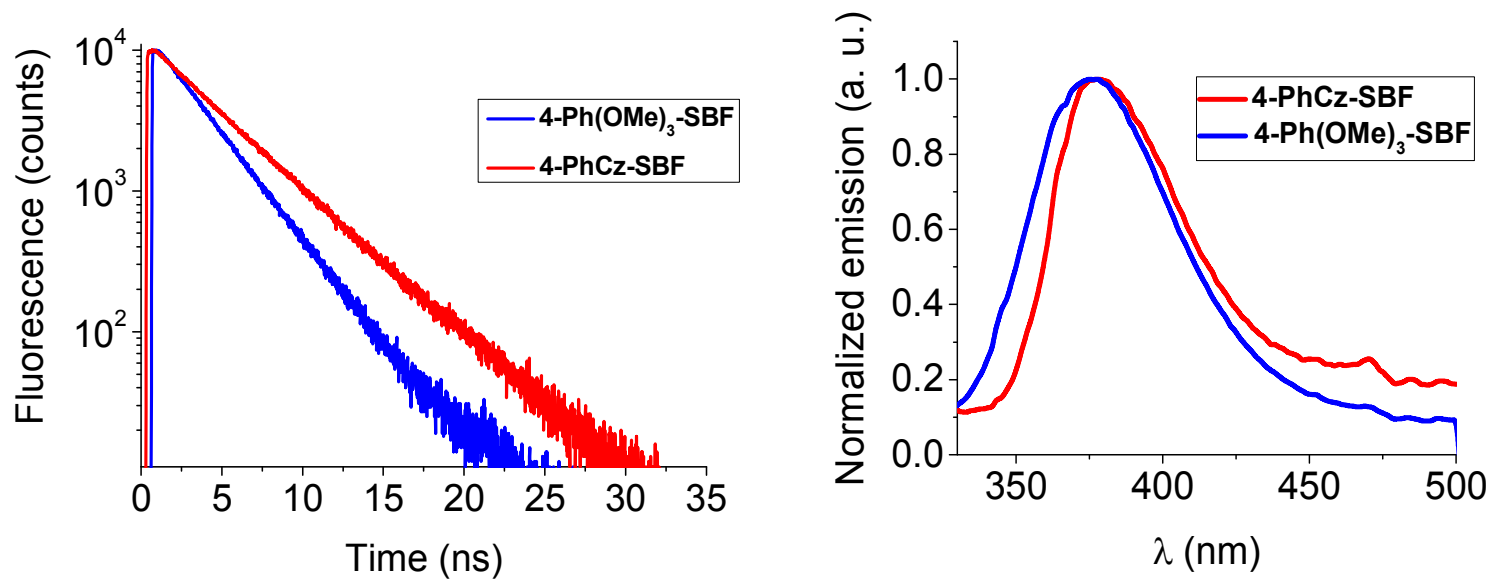

Figure 8. Left: Fluorescence decay curves of 4-PhCz-SBF (red line) and 4-Ph(OMe) ${ }_{3}-\mathbf{S B F}$ (blue line) in cyclohexane $\left(\lambda_{\text {exc }}=300 \mathrm{~nm}, \lambda_{\mathrm{em}}=375 \mathrm{~nm}\right)$, right: solid state emission of 4-PhCz-SBF (red line, $\lambda_{\mathrm{exc}}=280 \mathrm{~nm}$ ) and 4-Ph(OMe) $)_{3}-\mathbf{S B F}$ (blue line, $\lambda_{\mathrm{exc}}=280 \mathrm{~nm}$ ).

The fluorescence decays were recorded in cyclohexane and successfully fitted by single exponentials (figure 8-left) indicating a unique emission from the excited state $\mathrm{S}_{1}$ to $\mathrm{S}_{0}$. The lifetime of 4-PhCz-SBF, 4.0 ns, is close to that reported for SBF and 4-Ph-SBF (4.6 and 4.2 ns, resp. $^{28}$ ) and shorter than that reported for $\mathbf{N}-\mathbf{P h C z}(6.44$ or $6.3 \mathrm{~ns}) .{ }^{54,55}$ The lifetime of 4$\mathbf{P h}(\mathbf{O M e})_{3}$-SBF is shorter (2.8 ns) than those exposed above. For both 4-Ph(OMe) ${ }_{3}$-SBF and 4PhCz-SBF, the non-radiative rate constant $\left(\mathrm{k}_{\mathrm{nr}}\right)$ was calculated at $1.4 / 1.2 \times 10^{8} \mathrm{~s}^{-1}$ resp., similar to those of SBF or 4-Ph-SBF (1.3 or $1.4 \times 10^{8} \mathrm{~s}^{-1}$ ). This shows that the substitution of the phenyl unit by three methoxy groups or by a carbazole unit does not allow additional non-radiative pathways of the excited state deactivation process. The radiative rate constant $\left(\mathrm{k}_{\mathrm{r}}\right)$ of 4-Ph(OMe $)_{3}$-SBF is however twice that of 4-PhCz-SBF $\left(2.1\right.$ vs $\left.1.2 \times 10^{8} \mathrm{~s}^{-1}\right)$ and hence at the origin of the higher quantum yield of the former.

The solid state emission of $\mathbf{4 - P h}(\mathbf{O M e})_{3}$-SBF $(\lambda \max =378 \mathrm{~nm})$ is very similar to that of its solution spectrum with only a slight red shift of $3 \mathrm{~nm}$ (figure 8 right). Contrariwise, the emission spectrum of 4-PhCz-SBF losses its resolution and appears red-shifted by ca $33 \mathrm{~nm}$ compare to 
its solution spectrum. This may indicate strong interactions in the solid state, which can be attributed to the phenyl-carbazole fragment in accordance with the short $\mathrm{C} / \mathrm{C}$ distances observed in the crystal packing (see above).

The triplet energies $\left(\mathrm{E}_{\mathrm{T}}\right)$ were determined from the emission spectra at $77 \mathrm{~K}$ in 2-Me-THF (Figure 9-top). Both 4-PhCz-SBF and 4-Ph(OMe) ${ }_{3}$-SBF display a similar emission spectrum with a first phosphorescence band recorded at 442 and $437 \mathrm{~nm}$ leading to $\mathrm{E}_{\mathrm{T}}$ of $2.80 \mathrm{eV}$ and 2.84 eV respectively. The $\mathrm{E}_{\mathrm{T}}$ of both 4-Ph(OMe)$)_{3}-\mathbf{S B F}$ and 4-PhCz-SBF are very similar to those of SBF and 4-Ph-SBF (2.87 and $2.77 \mathrm{eV}$ resp. $){ }^{28}$ This is due to a similar localization of the triplet exciton, delocalized on the substituted fluorene core with a weak contribution of the pendant phenyl ring (Figure 9-bottom). This is very different to the HOMO and LUMO distribution, in which the pendant phenyl ring has a significant contribution for both molecules (Figure 5). This finding could be very useful to further tune the singlet and triplet energies of 4-substituted SBFs. Phosphorescence decay was measured and the lifetime of the T1 state of $\mathbf{4 - P h}(\mathbf{O M e})_{3}-\mathbf{S B F}$ and 4-PhCz-SBF was found to be very long, 4.6 and 4 s, respectively. Finally, both 4-Ph(OMe) ${ }_{3}$ SBF and 4-PhCz-SBF possess an $\mathrm{E}_{\mathrm{T}}$ higher than that of the blue phosphor FIrpic $\left(\mathrm{E}_{\mathrm{T}}: 2.62 \mathrm{eV}\right)^{56}$ being hence perfectly adapted to host it in optoelectronic devices. 

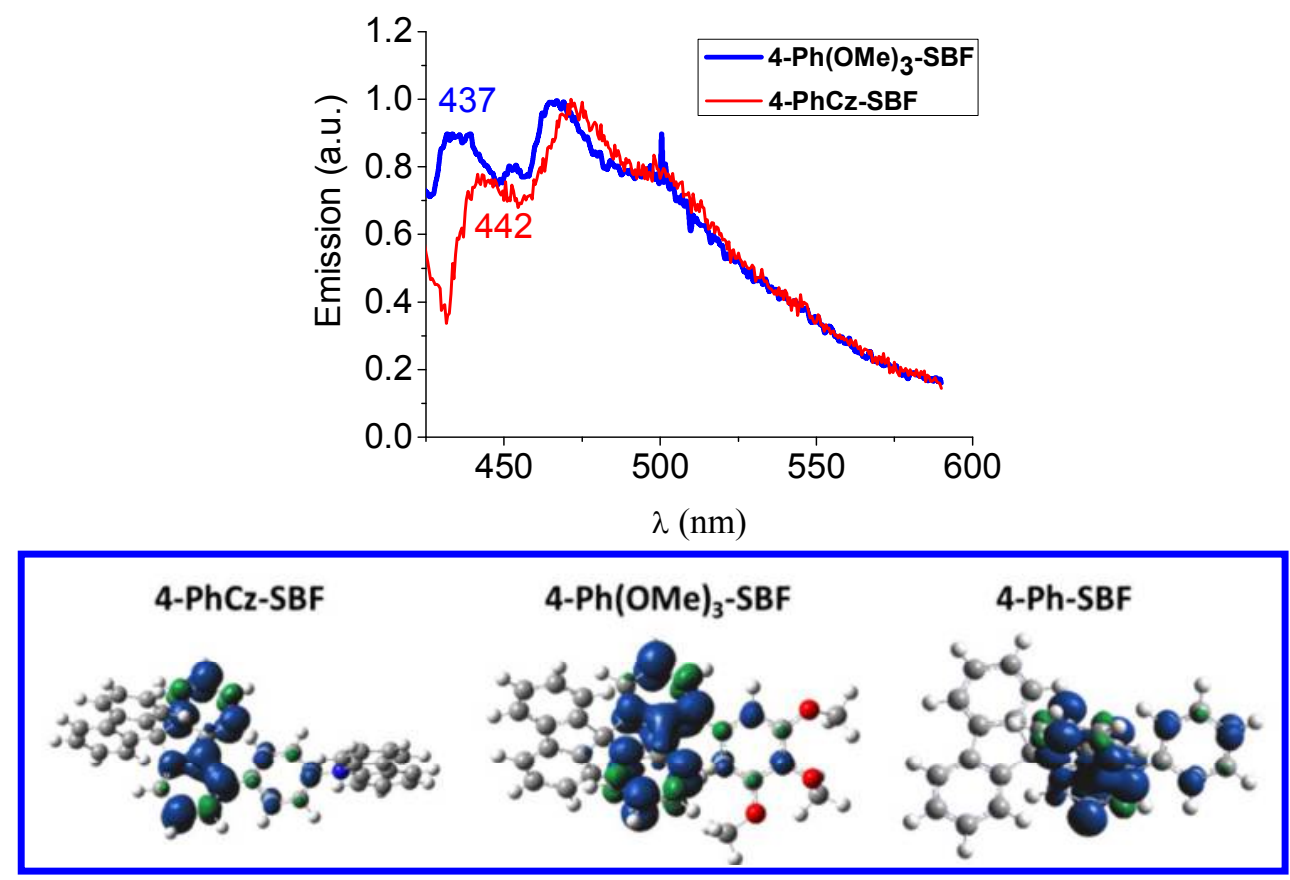

Figure 9. Top: Emission spectra at $77 \mathrm{~K}$ in 2-Me-THF of 4-PhCz-SBF (red line) and

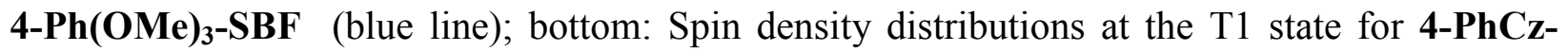
SBF, 4-Ph(OMe) ${ }_{3}$-SBF and 4-Ph-SBF (isovalue of 0.004)

Green (dopant $\operatorname{Ir}(\text { ppy) })_{3}$ : tris[2-phenylpyridinato- $\left.\mathrm{C}^{2}, N\right]$ iridium(III)) and sky blue (dopant FIrpic: bis[2-(4,6-difluorophenyl)pyridinato- $\left.{ }^{2}, N\right]$ (picolinato)iridium(III)) PhOLEDs with 4-PhCz-SBF or 4-Ph(OMe) $)_{3}-\mathbf{S B F}$ as the host were fabricated, characterised and their performances compared to that of other PhOLEDs using different 4-substituted-SBFs as host. The device architecture is given in the experimental part. In order to accurately compare the efficiency of the hosts in the device, we deliberately use the same PhOLED structure as that used in previous works. ${ }^{28,32,40} \mathrm{It}$ should be also mentioned that the devices are fabricated without light extraction enhancement system and the phosphorescent emitters are not particularly oriented. We believe that a device optimisation with these specific hosts will lead to even further higher efficiencies.

Table 3. Green $\left(\operatorname{Ir}(\text { ppy })_{3}\right)$ and blue (FIrpic) devices performances 


\begin{tabular}{|c|c|c|c|c|}
\hline & $4-\mathrm{Ph}(\mathrm{OMe})_{3^{-}}$ & BF & 4-PhCz-SBF & \\
\hline dopant & $\operatorname{Ir}(\text { ppy })_{3} 10 \%$ & FIrpic $20 \%$ & $\operatorname{Ir}(\text { ppy })_{3} 10 \%$ & FIrpic $17 \%$ \\
\hline Von $@ \mathrm{~L}=1$ & 4.3 & 4.2 & 3.7 & 3.75 \\
\hline $\mathrm{CE}(@ \mathrm{~J}=1)$ & 56.4 & 22.5 & 51.4 & 17.6 \\
\hline CE (@J=10) & 43.3 & 19.7 & 44.7 & 16.5 \\
\hline $\mathrm{CE}_{\max }(@ \mathrm{~J}=\mathrm{x})$ & $78.0(0.03)$ & $24.2(2.66)$ & $67.9(0.04)$ & $18.0(1.8)$ \\
\hline $\mathrm{PE}(@ \mathrm{~J}=1)$ & 27.0 & 12.2 & 26.6 & 10.1 \\
\hline $\operatorname{PE}(@ \mathrm{~J}=10)$ & 16.6 & 8.2 & 17.9 & 7.5 \\
\hline $\mathrm{PE}_{\max }(@ \mathrm{~J}=\mathrm{x})$ & $48.1(0.03)$ & $13.9(0.34)$ & $45.4(0.04)$ & $11.0(0.14)$ \\
\hline EQE (@J=1) & 14.6 & 8.9 & 13.2 & 6.5 \\
\hline EQE (@J=10) & 11.2 & 7.8 & 11.5 & 6.1 \\
\hline $\mathrm{EQE}_{\max }(@ \mathrm{~J}=\mathrm{x})$ & $20.2(0.03)$ & $9.6(2.66)$ & $17.5(0.04)$ & $6.7(1.8)$ \\
\hline
\end{tabular}

Von (V); CE (cd/A); PE (lm/W); EQE (\%); L (cd/m²); J (mA/ $\left.\mathrm{cm}^{2}\right)$

Green PhOLEDs (figure 10 and SI) with 4-PhCz-SBF as the host present a high maximum External Quantum Efficiencies (EQE) reaching 17.5\%. The corresponding Current Efficiency (CE) and Power Efficiency (PE) are recorded at $67.9 \mathrm{~cd} / \mathrm{A}$ and $45.4 \mathrm{~lm} / \mathrm{W}$ for 4-PhCz-SBF (figure 10). Device based on 4-Ph(OMe) $)_{3}$-SBF displays higher performance in identical experimental conditions with a very high EQE of $20.2 \%$ and corresponding $\mathrm{CE}$ of $78.0 \mathrm{~cd} / \mathrm{A}$ and $\mathrm{PE}$ of $48.1 \mathrm{~lm} / \mathrm{W}$ for $\mathbf{4 - P h}(\mathbf{O M e})_{3}$-SBF (figure 10). One can note that the turn-on voltage Von (defined as the driving voltage to achieve the brightness of $1 \mathrm{~cd} / \mathrm{m}^{2}$ ) of $4-\mathbf{P h}(\mathbf{O M e})_{3}-\mathbf{S B F}(4.3 \mathrm{~V}$ ) is higher than that of 4-PhCz-SBF (3.7 V), translating a better charges injection in the former in accordance with the different energy gap of the molecules (Table 1). Finally, the electroluminescent spectra of both devices exclusively display the emission of the phosphor $\operatorname{Ir}(\mathrm{ppy})_{3}$ in accordance with the emission of the pure $\operatorname{Ir}(\mathrm{ppy})_{3}{ }^{57}$ 

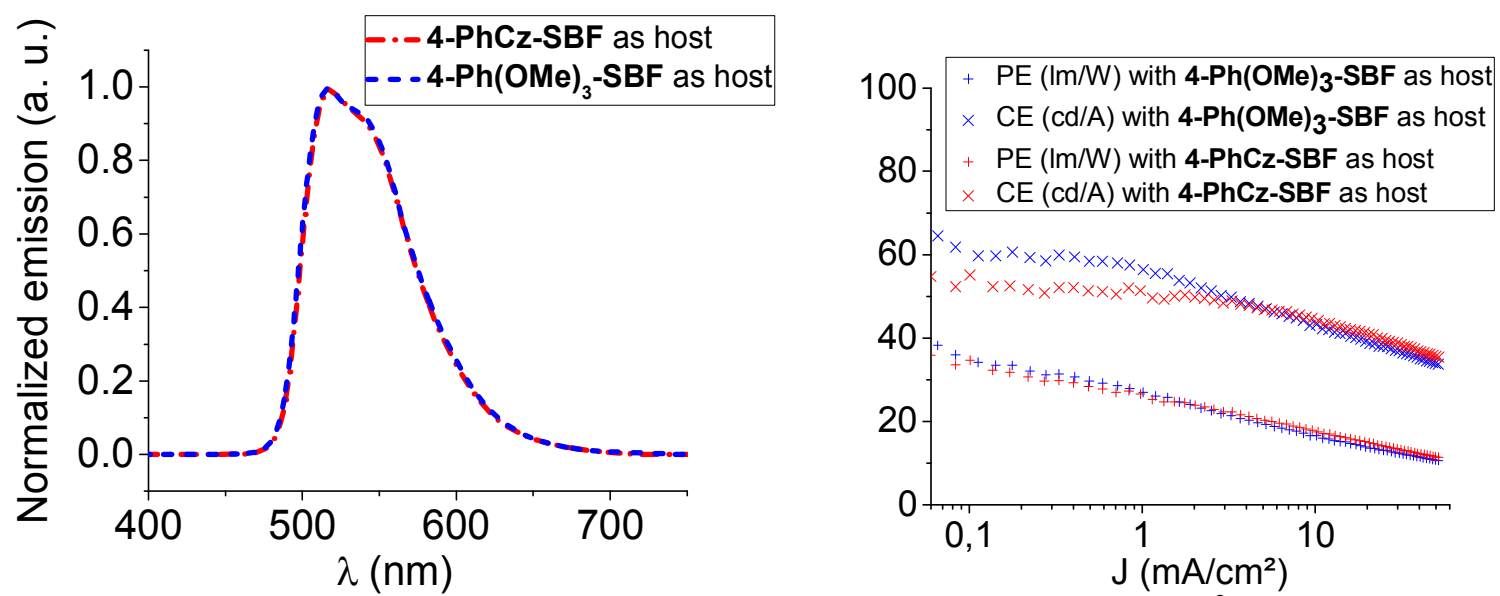

Figure 10. Left: Normalized electroluminescent spectrum at $10 \mathrm{~mA} / \mathrm{cm}^{2}$ of the green devices using 4-PhCz-SBF (red) or 4-Ph(OMe) ${ }_{3}$-SBF (blue) as host doped with $\operatorname{Ir}(\mathrm{ppy})_{3}(10 \%$ in mass) as emitting layer; right: Current efficiency $(\mathrm{CE}, \mathrm{Cd} / \mathrm{A}, \times)$ and power efficiency $(\mathrm{PE}, \mathrm{lm} / \mathrm{W},+)$ versus current density of the green devices using 4-PhCz-SBF (red) or 4-Ph(OMe) ${ }_{3}-\mathbf{S B F}$ (blue) as host doped with $\operatorname{Ir}(\mathrm{ppy})_{3}(10 \%$ in mass $)$ as emitting layer.

Sky Blue PhOLEDs were also fabricated and characterized (figure 11 and SI). With 4-PhCzSBF as the host, the maximum EQE reaches $6.7 \%$ with corresponding $\mathrm{CE}$ and $\mathrm{PE}$ of $18.0 \mathrm{~cd} / \mathrm{A}$ and $9.8 \mathrm{~lm} / \mathrm{W}$. As observed above for green devices, PhOLEDs based on 4-Ph(OMe) ${ }_{3}-\mathbf{S B F}$ display even higher performances with a maximum EQE as high as 9.6\% with corresponding CE and $\mathrm{PE}$ of $24.2 \mathrm{~cd} / \mathrm{A}$ and $12.0 \mathrm{~lm} / \mathrm{W}$. Similar conclusion than those exposed above can be drawn for Von. The EL spectra display exclusively the emission of the blue dopant at 474/498 nm for 4-Ph(OMe) $)_{3}$-SBF and 475/500 nm for 4-PhCz-SBF in accordance with photoluminescence of pure FIrpic film $(475 / 500 \mathrm{~nm}){ }^{56}$ The performance of 4-Ph(OMe) $)_{3} \mathbf{S B F}$ is hence higher than those previously reported for 4-substituted SBF incorporating electron poor fragments. ${ }^{33,32}$ The hole carrier mobility of 4-PhCz-SBF and 4-Ph(OMe) $)_{3}-\mathbf{S B F}$ have been finally determined by Space Charge Limited Current (SCLC) measurements. Thus, the hole mobility of 4-PhCz-SBF and 4-Ph(OMe) ${ }_{3}$-SBF extracted from the Mott-Gurney law (see SI) is about $4.1 \times 10^{-6}$ and 


\section{$1.1 \times 10^{-5} \mathrm{~cm}^{2} / \mathrm{V} . \mathrm{s}$ respectively. The hole mobility of 4-Ph(OMe)$)_{3}-\mathbf{S B F}$ appears hence} significantly higher than that of 4-PhCz-SBF. This feature can be one of those involved in the higher PhOLEDs performance observed for 4-Ph(OMe) ${ }_{3}$-SBF compared to 4-PhCz-SBF.
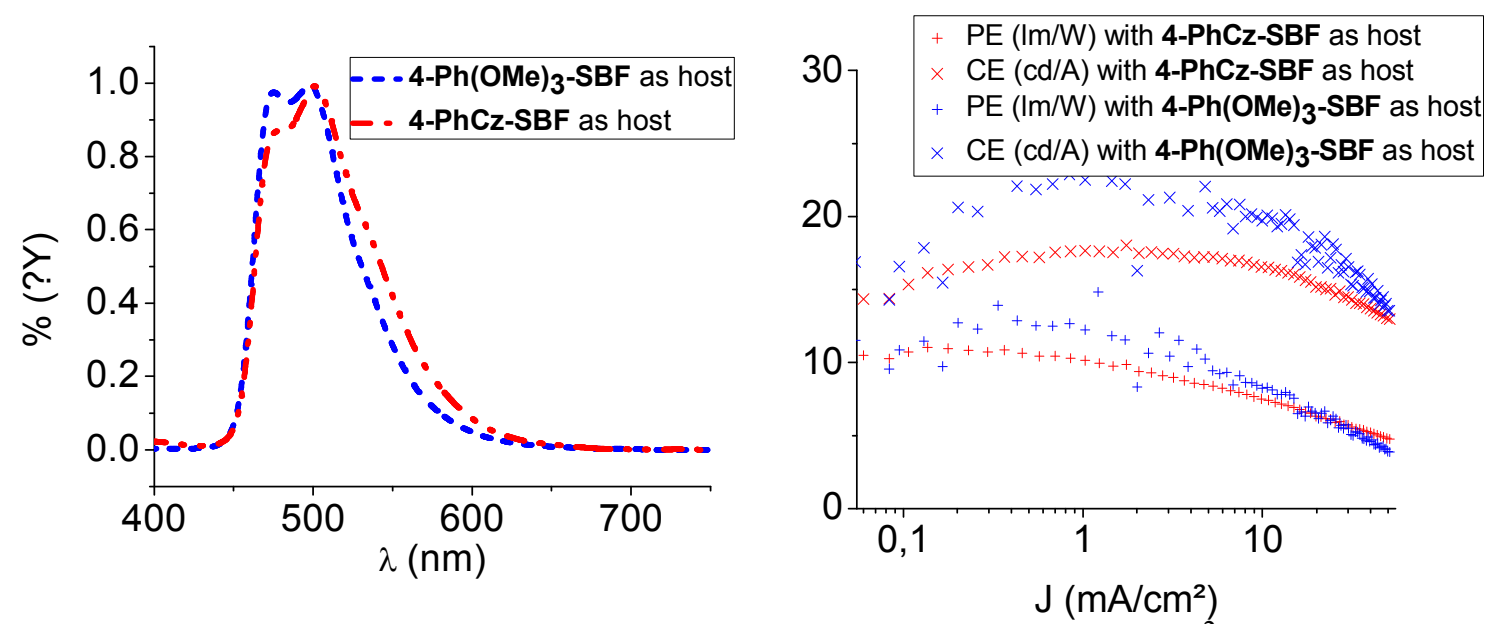

Figure 11. Left: Normalized electroluminescent spectrum at $10 \mathrm{~mA} / \mathrm{cm}^{2}$ of the blue devices using 4-PhCz-SBF (red) or 4-Ph(OMe) ${ }_{3}$-SBF (blue) as host doped with FIrpic (17-20\% in mass) as emitting layer; right: Current efficiency $(\mathrm{CE}, \mathrm{Cd} / \mathrm{A}, \times)$ and power efficiency $(\mathrm{PE}, \mathrm{lm} / \mathrm{W}$, + ) versus current density of the green devices using 4-PhCz-SBF (red) or 4-Ph(OMe) ${ }_{3}-\mathbf{S B F}$ (blue) as host doped with FIrpic (17-20\% in mass) as emitting layer

The performances of 4-Ph(OMe) $)_{3}-\mathbf{S B F}$ appear promising for a non-bipolar molecule. Indeed, the high performances are often obtained with molecules incorporating both electron-donating and electron-withdrawing fragments. Herein, with only an electron-donating unit, the corresponding devices display high performance, which could be surely further increased by device engineering or incorporation of an acceptor unit to decrease the LUMO energy level.

\section{CONCLUSIONS}

In summary, this work reports the first examples of electron-rich 4-substituted-SBFs, 4-PhCz-SBF and 4-Ph(OMe) $)_{3}$-SBF, for green/blue PhOLED applications. Thanks to a detailed 
structure-properties relationship study, this work shows that the incorporation of electron-rich moieties in $\mathrm{C} 4$ of the $\mathrm{SBF}$ core induces unique properties, very different to those previously reported for this family of molecules. Thus, the electronic properties of these dyes can be modulated not only by the nature of the fragment borne by the SBF but also by the angle formed between this fragment and the SBF moiety. Of particular interest, the structured emission of 4-PhCz-SBF with a short Stokes shift appears to be unique in the 4-substituted SBFs family. The very similar geometry of its ground and first excited state appears herein as the first step in the understanding of the peculiar fluorescence of 4-substituted SBFs. Due to their high $\mathrm{E}_{\mathrm{T}}$ and high HOMO energy levels, both 4-PhCz-SBF and 4-Ph(OMe) ${ }_{3}-\mathbf{S B F}$ have been successfully incorporated as host in green and blue PhOLEDs with high performance (EQE of 20.2\% and $9.6 \%$ respectively) and low threshold voltages. These performances are, to the best of our knowledge, among the highest reported to date for 4-substituted SBF derivatives, highlighting the strong potential of 4-Ph(OMe) ${ }_{3}$-SBF (and more generally of the global approach) as host in blue PhOLEDs. Bipolar hosts constructed on a similar design are currently developed in our laboratories.

\section{ASSOCIATED CONTENT}

Supporting Information: Details on material and methods, thermal properties, electrochemical properties, structural properties, photophysical properties, molecular modelling, device fabrication and characterization, copy of NMR spectra.

\section{AUTHOR INFORMATION}

\section{Corresponding Author}

*e-mail: cyril.poriel@univ-rennes1.fr, joelle.rault-berthelot@univ-rennes1.fr 


\section{Author Contributions}

The manuscript was written through contributions of all authors. All authors have given approval to the final version of the manuscript.

\section{Funding Sources}

The ANR 'Men In Blue' (n¹4-CE05-0024) and the ANR 'HOME OLED' (n`11-BS07-020-01) provided the financial support.

\section{ACKNOWLEDGMENT}

The authors thank the CDIFX (Rennes) for X-Ray data collection, the CRMPO and P. Jéhan (Rennes) for mass spectrometry, GENCI (France) for allocation of computing time at CINES (Montpellier) under project c2016085032. CP and CQ wish to highly thank Prof J. Cornil (Mons) for his precious help in theoretical calculations and Dr R. Métivier (Cachan) for helpful photophysics discussions. We wish to thank the ANR 'Men In Blue' (n 14-CE05-0024) for financial support and for a post-doctoral grant (CQ) and the ANR 'HOME OLED' (n¹1-BS07020-01) for financial support and for a studentship (ST).

\section{REFERENCES}

1. Romain, M.; Tondelier, D.; Vanel, J.-C.; Geffroy, B.; Jeannin, O.; Rault-Berthelot, J.; Métivier, R.; Poriel, C. Dependence of the Properties of Dihydroindenofluorene Derivatives on Positional Isomerism Angew. Chem. Int. Ed. 2013, 52, 14147-14151.

2. Poriel, C.; Liang, J.-J.; Rault-Berthelot, J.; Barrière, F.; Cocherel, N.; Slawin, A. M. Z.; Horhant, D.; Virboul, M.; Alcaraz, G.; Audebrand, N.; Vignau, L.; Huby, N.; Wantz, G.; Hirsch, L. Dispirofluorene-Indenofluorene Derivatives as New Building Blocks for Blue Organic Electroluminescent Devices and Electroactive Polymers. Chem.Eur.J. 2007, 13, 10055-10069.

3. Cocherel, N.; Poriel, C.; Vignau, L.; Bergamini, J.-F.; Rault-Berthelot, J. DiSpiroXanthene-IndenoFluorene: A New Blue Emitter for Nondoped Organic Light Emitting Diode Applications. Org. Lett. 2010, 12, 452-455.

4. Thirion, D.; Rault-Berthelot, J.; Vignau, L.; Poriel, C. Synthesis and Properties of a Blue Bipolar Indenofluorene Emitter Based on a D- $\pi$-A Design. Org Lett. 2011, 13, 4418-4421. 
5. Thirion, D.; Romain, M.; Rault-Berthelot, J.; Poriel, C. Intramolecular Excimer Emission as a Blue Light Source in Fluorescent Organic Light Emitting diodes: A Promising Molecular Design. J. Mater. Chem. 2012, 22, 7149-7157.

6. Saragi, T. P. I.; Spehr, T.; Siebert, A.; Fuhrmann-Lieker, T.; Salbeck, J. Spiro Compounds for Organic Optoelectronics. Chem. Rev. 2007, 107, 1011-1065.

7. Xing, X.; Xiao, L.; Zheng, L.; Hu, S.; Chen, Z.; Qu, B.; Gong, Q. Spirobifluorene Derivative: A Pure Blue Emitter $(\mathrm{CIEy} \approx 0.08)$ with High Efficiency and Thermal Stability. $J$. Mater. Chem. 2012, 22, 15136.

8. Yu, W.-L.; Pei, J.; Huang, W.; Heeger, A. J. Spiro-Functionalized Polyfluorene Derivatives as Blue Light-Emitting Materials. Adv. Mater. 2000, 12, 828-831.

9. Tang, S.; Liu, M.; Lu, P.; Xia, H.; Li, M.; Xie, Z.; Shen, F. Z.; Gu, C.; Wang, H.; Yang, B.; Ma, Y. A Molecular Glass for Deep-Blue Organic Light-Emitting Diodes Comprising a 9,9'Spirobifluorene Core and Peripheral Carbazole Groups. Adv. Funct. Mat. 2007, 17, 2869-2877.

10. Park, Y.-I.; Son, J.-H.; Kang, J.-S.; Kim, S.-K.; Lee, J.-H.; Park, J.-W. Synthesis and Electroluminescence Properties of Novel Deep Blue Emitting 6,12-Dihydro-diindeno[1,2b;1',2'-e] Pyrazine Derivatives. Chem. Commun. 2008, 2143-2145.

11. Tao, S.; Peng, Z.; Zhang, X.; Wang, P.; Lee, C.-S.; Lee, S.-T. Highly Efficient NonDoped Blue Organic Light-Emitting Diodes Based on Fluorene Derivatives with High Thermal Stability. Adv. Funct. Mater. 2005, 15, 1716-1721.

12. Poriel, C.; Rault-Berthelot, J.; Thirion, D.; Barrière, F.; Vignau, L. Blue Emitting $3 \pi-$ 2 Spiro Terfluorene-Indenofluorene Isomers: A Structure-Properties Relationship Study. Chem. Eur. J. 2011, 17, 14031-14046.

13. Poriel, C.; Cocherel, N.; Rault-Berthelot, J.; Vignau, L.; Jeannin, O. Incorporation of Spiroxanthene Units in Blue-Emitting Oligophenylene Frameworks: A New Molecular Design for OLED Applications. Chem. Eur. J. 2011, 17, 12631-12645.

14. Xie, L.-H.; Liang, J.; Song, J.; Yin, C.-R.; Huang, W. Spirocyclic Aromatic Hydrocarbons (SAHs) and their Synthetic Methodologies. Curr. Org. Chem. 2010, 14, 21692195.

15. Yang, X.; Xu, X.; Zhou, G. Recent Advances of the Emitters for High Performance Deep-Blue Organic Light-Emitting Diodes. J. Mater. Chem. C 2015, 3, 913-944.

16. Lee, K. H.; Kwon, Y. K.; Lee, J. Y.; Kang, S. O.; Yook, K. S.; Jeon, S. O.; Lee, J. Y.; Yoon, S. S. Highly Efficient Blue Organic Light-Emitting Diodes Based on 2(Diphenylamino)fluoren-7-ylvinylarene Derivatives that Bear a tert-Butyl Group. Chem. Eur. J. 2011, 17, 12994-13006.

17. Dumur, F. Deep-blue Organic Light-emitting Diodes: From Fluorophores to Phosphors for High-efficiency Devices. In Advanced Surface Engineering Materials, Scrivener Publishing: 2016 pp 561-634.

18. Ren, H.; Tao, Q.; Gao, Z.; Liu, D. Synthesis and Properties of Novel SpirobifluoreneCored Dendrimers. Dyes and Pigments 2012, 94, 136-142.

19. Peng, Z.; Tao, S.; Zhang, X.; Tang, J.; Chun, S. L.; Lee, S.-T. Electroluminescent Devices: Influence of Substituents on Thermal Properties, Photoluminescence, and Electroluminescence. J. Phys. Chem. C 2008, 112, 2165-2169.

20. Chao, T.-C.; Lin, y.-T.; Yang, C. Y.; Hung, C.-H.; Chou, H.-C.; Wu, C.-C.; Wong, K.-T. Highly Efficient UV Organic Light-Emitting Devices Based on Bi(9,9-diarylfluorene)s. Adv. Mater. 2005, 992-996. 
21. Kim, Y.-H.; Shin, D.-C.; Kim, S.-H.; Ko, C.-H.; Yu, H.-S.; Chae, Y.-S.; Kwon, S.-K. Novel Blue Emitting Material with High Color Purity. Adv. Mater. 2001, 13, 1690-1693.

22. Yi, J.; Wang, Y.; Luo, Q.; Lin, Y.; Tan, H.; Wang, H.; Ma, C.-Q. A 9,9'-spirobi[9Hfluorene]-Cored Perylenediimide Derivative and its Application in Organic Solar Cells as a NonFullerene Acceptor. Chem. Commun. 2016, 52, 1649-1652.

23. Wu, X.-F.; Fu, W.-F.; Xu, Z.; Shi, M.; Liu, F.; Chen, H.-Z.; Wan, J.-H.; Russell, T. P. Spiro Linkage as an Alternative Strategy for Promising Nonfullerene Acceptors in Organic Solar Cells. Adv. Funct. Mater. 2015, 25, 5954-5966.

24. Bulut, I.; Chavez, P.; Fall, S.; Mery, S.; Heinrich, B.; Rault-Berthelot, J.; Poriel, C.; Leveque, P.; Leclerc, N. Incorporation of Spirobifluorene Regioisomers in Electron-Donating Molecular Systems for Organic Solar Cells. RSC Adv. 2016, 6, 25952-25959.

25. Xia, D.; Gehrig, D.; Guo, X.; Baumgarten, M.; Laquai, F.; Mullen, K. A spiro-Bifluorene Dased 3D Electron Acceptor with Dicyanovinylene Substitution for Solution-Processed NonFullerene Organic Solar Cells. J. Mater. Chem. A 2015, 3, 11086-11092.

26. Li, S.; Liu, W.; Shi, M.; Mai, J.; Lau, T.-K.; Wan, J.; Lu, X.; Li, C.-Z.; Chen, H. A Spirobifluorene and Diketopyrrolopyrrole Moieties Based Non-Fullerene Acceptor for Efficient and Thermally Stable Polymer Solar Cells with High Open-Circuit Voltage. Energy Environ. Sci 2016, 9, 604-610.

27. Song, K. C.; Singh, R.; Lee, J.; Sin, D. H.; Lee, H.; Cho, K. Propeller-Shaped Small Molecule Acceptors Containing a 9,9'-Spirobifluorene Core with Imide-Linked Perylene Diimides for Non-Fullerene Organic Solar Cells. J. Mater. Chem. C 2016. doi : 10.1039/C6TC03676G

28. Thiery, S.; Tondelier, D.; Declairieux, C.; Seo, G.; Geffroy, B.; Jeannin, O.; RaultBerthelot, J.; Métivier, R.; Poriel, C. 9,9'-Spirobifluorene and 4-Phenyl-9,9'-Spirobifluorene: Pure Hydrocarbon Small Molecules as Hosts for Efficient Green and Blue PhOLEDs. J. Mater. Chem. C 2014, 2, 4156-4166.

29. Jiang, Z.; Yao, H.; Zhang, Z.; Yang, C.; Liu, Z.; Tao, Y.; Qin, J.; Ma, D. .: Novel Oligo9,9'-spirobifluorenes through ortho-Linkage as Full Hydrocarbon Host for Highly Efficient Phosphorescent OLEDs. Org. Lett. 2009, 11, 2607-2610.

30. Fan, C.; Chen, Y.; Gan, P.; Yang, C.; Zhong, C.; Qin, J.; Ma, D. High Triplet-Energy Pure Hydrocarbon Host for Blue Phosphorescent Emitter. Org. Lett. 2010, 12, 5648-5651.

31. Cui, L.-S.; Xie, Y.-M.; Wang, Y.-K.; Zhong, C.; Deng, Y.-L.; Liu, X.-Y.; Jiang, Z.-Q.; Liao, L.-S. Exciton Harvesting in Both Phosphorescent and Fluorescent Light-Emitting Devices. Adv. Mater. 2015, 27, 4213-4217.

32. Thiery, S.; Tondelier, D.; Declairieux, C.; Geffroy, B.; Jeannin, O.; Métivier, R.; RaultBerthelot, J.; Poriel, C. 4-Pyridyl-9,9'-spirobifluorenes as Host Materials for Green and Sky-Blue Phosphorescent OLEDs. J. Phys. Chem. C 2015, 119, 5790-5805.

33. Thiery, S.; Declairieux, C.; Tondelier, D.; Seo, G.; Geffroy, B.; Jeannin, O.; Métivier, R.; Rault-Berthelot, J.; Poriel, C. 2-Substituted vs 4-Substituted-9,9'-Spirobifluorene Host Materials for Green and Blue Phosphorescent OLEDs: a Structure-Property Relationship Study. Tetrahedron 2014, 70, 6337-6351.

34. Thiery, S.; Tondelier, D.; Geffroy, B.; Jacques, E.; Robin, M.; Métivier, R.; Jeannin, O.; Rault-Berthelot, J.; Poriel, C. Spirobifluorene-2,7-dicarbazole-4'-phosphine Oxide as Host for High-Performance Single-Layer Green Phosphorescent OLED Devices. Org. Lett. 2015, 17, 4682-4685. 
35. Jang, S. E.; Joo, C. W.; Jeon, S. O.; Yook, K. S.; Lee, J. Y. The Relationship Between the Substitution Position of the Diphenylphosphine Oxide on the Spirobifluorene and Device Performances of Blue Phosphorescent Organic Light-Emitting Diodes. Org. Electron. 2010, 11, 1059-1065.

36. Romain, M.; Tondelier, D.; Jeannin, O.; Geffroy, B.; Rault-Berthelot, J.; Poriel, C. Properties Modulation of Prganic Semi-Conductors Based on a Donor-Spiro-Acceptor (D-spiroA) Molecular Design: New Host Materials for Efficient Sky-Blue PhOLEDs. J. Mater. Chem. C 2015, 3, 9701-97014.

37. Romain, M.; Tondelier, D.; Geffroy, B.; Shirinskaya, A.; Jeannin, O.; Rault-Berthelot, J.; Poriel, C. Spiro-Configured Phenyl Acridine Thioxanthene Dioxide as a Host for Efficient PhOLEDs. Chem. Commun. 2015, 51, 1313-1315.

38. Xue, M.-M.; Xie, Y.-M.; Cui, L.-S.; Liu, X.-Y.; Yuan, X.-D.; Li, Y.-X.; Jiang, Z.-Q.; Liao, L.-S. The Control of Conjugation Lengths and Steric Hindrance to Modulate AggregationInduced Emission with High Electroluminescence Properties and Interesting Optical Properties. Chem. Eur. J. 2016, 22, 916-924.

39. Xue, M.-M.; Huang, C.-C.; Yuan, Y.; Cui, L.-S.; Li, Y.-X.; Wang, B.; Jiang, Z.-Q.; Fung, M.-K.; Liao, L.-S. De Novo Design of Boron-Based Host Materials for Highly Efficient Blue and White Phosphorescent OLEDs with Low Efficiency Roll-Off. ACS Appl. Mater. Interfaces 2016, 8, 20230-20236.

40. Thiery, S.; Tondelier, D.; Geffroy, B.; Jeannin, O.; Rault-Berthelot, J.; Poriel, C. Modulation of the Physicochemical Properties of Donor-Spiro-Acceptor Derivatives through Donor Unit Planarisation: Phenylacridine versus Indoloacridine-New Hosts for Green and Blue Phosphorescent Organic Light-Emitting Diodes (PhOLEDs). Chem. Eur. J. 2016, 22, 1013610149 .

41. Zhang, Y.-X.; Ding, L.; Liu, X.-Y.; Chen, H.; Ji, S.-J.; Liao, L.-S. Spiro-Fused NPhenylcarbazole-Based Host Materials for Blue Phosphorescent Organic Light-Emitting Diodes. Org. Electron. 2015, 20, 112-118.

42. Seo, J.-A.; Gong, M. S.; Lee, J. Y. Thermally Stable Indoloacridine Type Host Material for High Efficiency Blue Phosphorescent Organic Light-Emitting Diodes. Org. Electron. 2014, 15, 3773-3779.

43. Poriel, C.; Rault-Berthelot, J.; Quinton, C.; Thiery, S.; Geffroy, B.; Tondelier, D.; Métivier, R. 9H-Quinolino[3,2,1-k]phenothiazine: A New Electron-Rich Fragment for Organic Electronics. Chem. Eur. J. 2016, 17930-17935

44. Wang, Y.-K.; Sun, Q.; Wu, S.-F.; Yuan, Y.; Li, Q.; Jiang, Z.-Q.; Fung, M.-K.; Liao, L.-S. Thermally Activated Delayed Fluorescence Material as Host with Novel Spiro-Based Skeleton for High Power Efficiency and Low Roll-Off Blue and White Phosphorescent Devices. Adv. Funct. Mat. 2016, 7929-7936

45. Thirion, D.; Poriel, C.; Barrière, F.; Métivier, R.; Jeannin, O.; Rault-Berthelot, J. Tuning the Optical Properties of Aryl-Substituted Dispirofluorene-Indenofluorene Isomers through Intramolecular Excimer Formation. Org. Lett. 2009, 11, 4794-4797.

46. Bondi, A., van der Waals Volumes and Radii. J. Phys. Chem. 1964, 68, 441-451.

47. Kulkarni, A. P.; Tonzola, C. J.; Babel, A.; Jenekhe, S. A. Electron Transport Materials for Organic Light-Emitting Diodes. Chem. Mater. 2004, 16, 4556-4573.

48. Poriel, C.; Ferrand, Y.; Le Maux, P.; Paul-Roth, C.; Simonneaux, G.; Rault-Berthelot, J. Anodic Oxidation and Physicochemical Properties of Various Porphyrin-Fluorenes or - 
Spirobifluorenes: Synthesis of New Polymers for Heterogeneous Catalytic Reactions. J. Electroanal. Chem. 2005, 583, 92-103.

49. Poriel, C.; Ferrand, Y.; Le Maux, P.; Rault-Berthelot, J.; Simonneaux, G. Organic CrossLinked Electropolymers as Supported Oxidation Catalysts: Poly((tetrakis $\left(9,9^{6}\right.$ spirobifluorenyl)porphyrin)manganese) Films. Inorg. Chem. 2004, 43, 5086-5095.

50. Ferrand, Y.; Poriel, C.; Le Maux, P.; Rault-Berthelot, J.; Simonneaux, G. Asymmetric Heterogeneous Carbene Transfer Catalyzed by Optically Active Ruthenium Spirobifluorenylporphyrin Polymers. Tetrahedron Asymmetry 2005, 16, 1463-1472.

51. Poriel, C.; Rault-Berthelot, J. Spirobifluorenyl-Porphyrins and their Derived Polymers for Homogeneous or Heterogeneous Catalysis. In 'Electrochemistry of N4 Macrocyclic metal complexes, Springer, Ed. 2016; Vol. 2, pp 345-393.

52. Dong, S.-C.; Gao, C.-H.; Yuan, X. D.; Cui, L.-S.; Jiang, Z.-Q.; Lee, S.-T.; Liao, L. S. Novel Dibenzothiophene Based Host Materials Incorporating Spirobifluorene for HighEfficiency White Phosphorescent Organic Light-Emitting Diodes. Org. Electron. 2013, 14, 902908.

53. Dong, S.-C.; Gao, C.-H.; Zhang, Z.-H.; Jiang, Z.-Q.; Lee, S.-T.; Liao, L. S. New Dibenzofuran/Spirobifluorene Hybrids as Thermally Stable Host Materials for Efficient Phosphorescent Organic Light-Emitting Diodes with Low Efficiency Roll-Off. Phys. Chem. Chem. Phys. 2012, 14, 14224-14228.

54. Lee, C.-C.; Leung, M.-K.; Lee, P.-Y.; Chiu, T.-L.; Lee, J.-H.; Liu, C.; Chou, P.-T. Synthesis and Properties of Oxygen-Linked N-Phenylcarbazole Dendrimers. Macromolecules 2012, 45, 751-765.

55. Sarkar, A.; Chakravorti, S. A Solvent-Dependent Luminescence Study on 9-Phenyl Carbazole. J. Lumin. 1998, 78, 205-211.

56. Baranoff, E.; Curchod, B. F. E. FIrpic: Archetypal Blue Phosphorescent Emitter for Electroluminescence. Dalton Trans. 2015, 44, 8318-8329.

57. Seo, J. H.; Han, N. S.; Shim, H. S.; Kwon, J. H.; Song, J. K. Phosphorescence Properties of Ir(ppy)3 Films. Bull. Korean Chem. Soc. 2011, 32, 1415.

\section{TABLE OF CONTENTS}




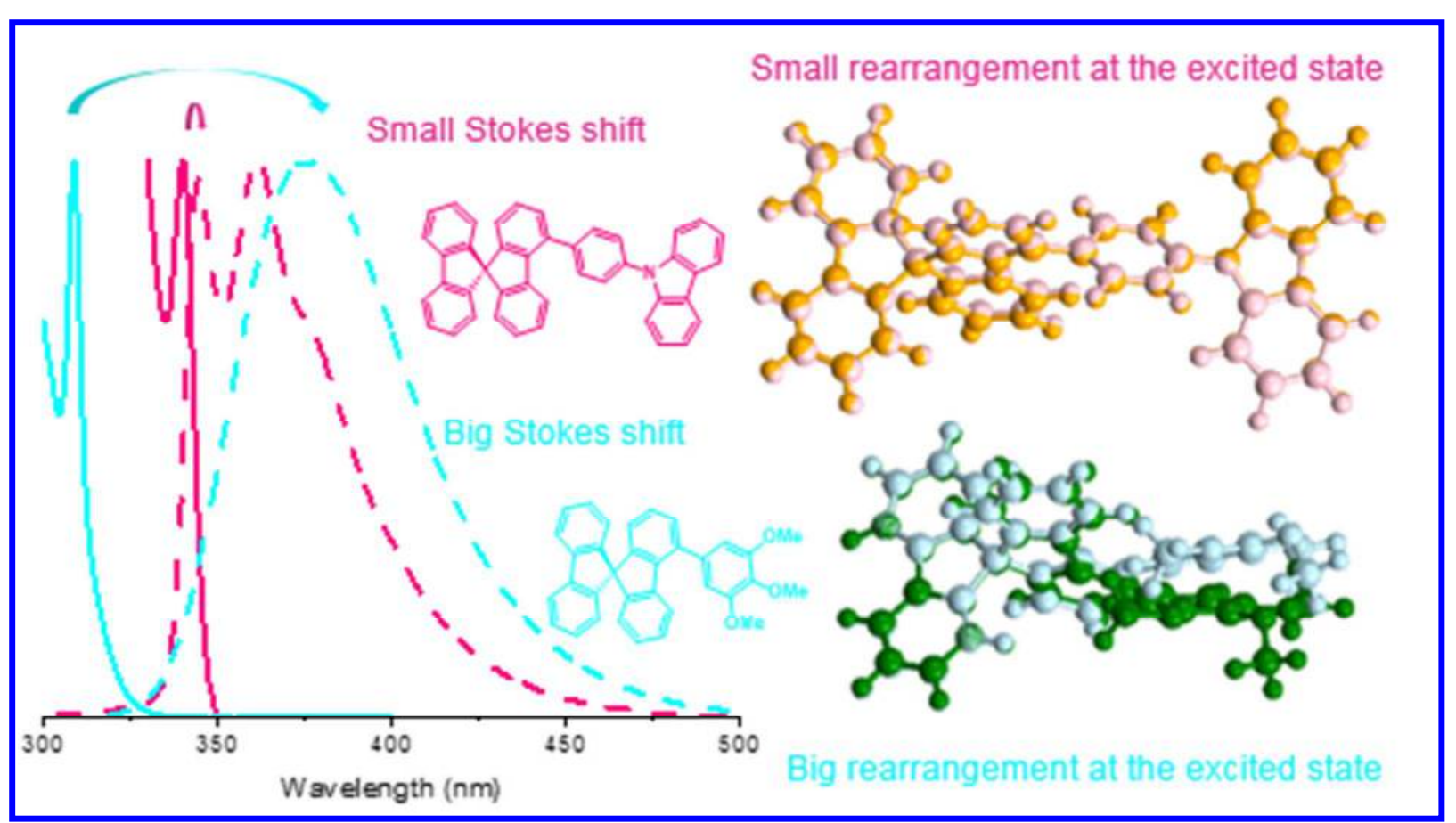

2 3 